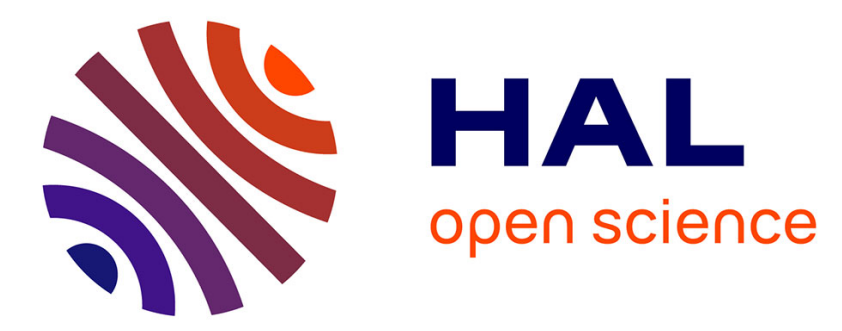

\title{
The crystallinity, thermal properties and microscopic morphology of di-block copolymers of L-lactide and several acrylates
}

Wei-Wei Wang, Long Jiang, Wu-Yang Ren, Chun-Mei Zhang, Chang-Zhen Man, Thien-Phap Nguyen, Yi Dan

\section{To cite this version:}

Wei-Wei Wang, Long Jiang, Wu-Yang Ren, Chun-Mei Zhang, Chang-Zhen Man, et al.. The crystallinity, thermal properties and microscopic morphology of di-block copolymers of L-lactide and several acrylates. RSC Advances, 2016, 6 (38), pp.31934-31946. 10.1039/c5ra24327k . hal-01723643

\section{HAL Id: hal-01723643 \\ https://hal.science/hal-01723643}

Submitted on 27 Apr 2020

HAL is a multi-disciplinary open access archive for the deposit and dissemination of scientific research documents, whether they are published or not. The documents may come from teaching and research institutions in France or abroad, or from public or private research centers.
L'archive ouverte pluridisciplinaire HAL, est destinée au dépôt et à la diffusion de documents scientifiques de niveau recherche, publiés ou non, émanant des établissements d'enseignement et de recherche français ou étrangers, des laboratoires publics ou privés. 


\title{
The crystallinity, thermal properties and microscopic morphology of di-block copolymers of L-lactide and several acrylates
}

\author{
Wei-Wei Wang, ${ }^{\text {ab }}$ Long Jiang, ${ }^{a}$ Wu-Yang Ren, ${ }^{a}$ Chun-Mei Zhang, ${ }^{\text {a }}$ Chang-Zhen Man, ${ }^{a}$ \\ Thien-Phap Nguyen ${ }^{\star b}$ and Yi Dan*a
}

In this paper a series of di-block copolymers of L-lactide and (meth)acrylate [(M)A, representing methyl methacrylate, tert-butyl acrylate and 2-ethylhexyl acrylate] were synthesized by varying the molecular weight of the polylactide (PLLA) macroinitiator and the structure of the (meth)acrylate monomers. The glass transition temperature, crystallinity and thermal stability of copolymers with different poly(meth) acrylate $[\mathrm{P}(\mathrm{M}) \mathrm{A}]$ blocks were investigated by differential scanning calorimetry (DSC) and thermogravimetric analysis (TGA). The results indicated that the glass transition temperature of the copolymers could be tuned by changing the chain structure and chain length of the $\mathrm{P}(\mathrm{M}) \mathrm{A}$ blocks. Besides, the crystallization of the copolymers was inhibited by the introduction of $\mathrm{P}(\mathrm{M}) \mathrm{A}$ blocks, and the toughness of the copolymers could be tuned. It is noted that the thermal stability of the copolymers depended on the type of P(M)A blocks and the PLLA/ $\mathrm{P}(\mathrm{M}) \mathrm{A}$ blocks ratio. Furthermore, the microphase separation of copolymers in thin films was observed by atomic force microscopy (AFM) and scanning electron microscopy (SEM), and the results showed that the composition of copolymers significantly affected the surface morphology of the block copolymer thin films.

\section{Introduction}

Poly(L-lactide) (PLLA) is considered to be one of the most promising biopolymers due to its unique properties $;^{1-7}$ many of the early applications of PLLA have been destined for biomedical fields, including in vivo degradable/resorbable medical implants, sutures and controlled drug delivery systems. ${ }^{5,6}$ In recent years, technological developments have made PLLA economically competitive with petroleum-derived plastics, ${ }^{6,7}$ and PLLA is now being considered as an ideal substitute to produce consumer goods such as packaging materials, cold drink bottles, carrier bags, and clothing. ${ }^{\mathbf{1 - 4 , 7}}$

However, PLLA exhibits a low heat distortion resistance due to its low glass transition temperature $\left(T_{\mathrm{g}}\right)$ at $c a .65{ }^{\circ} \mathrm{C} .{ }^{3,7}$ The drawback in heat distortion resistance together with its brittleness greatly limits its potential applications. Several approaches have been employed to improve its heat distortion resistance and thermal stability, such as the addition of nucleating agents, end group protection, cross-linking and use

${ }^{a}$ State Key Laboratory of Polymer Materials Engineering of China, Polymer Research Institute of Sichuan University, Chengdu 610065, P. R. China. E-mail: jianglong@ scu.edu.cn; brazilar@gmail.com; zhangzhang_87@126.com; manchangzhen@163. com; youyizaixin@163.com; danyi@scu.edu.cn; Fax: +86-28-85402465; Tel: +86-2885407286

${ }^{5}$ Institut des Matériaux Jean Rouxel, 2, rue de la Houssinière, 44322 Nantes Cedex 3, France. E-mail: Thien-Phap.Nguyen@cnrs-imn.fr; Fax: +33-02-40373991; Tel: +33-0240373976 of composites with fibers or nanoparticles. ${ }^{\mathbf{8}-11}$ However, high crystallinity or the cross-linked structure usually reduces the toughness and transparency of PLLA. ${ }^{\mathbf{8 , 1 2 , 1 3}}$ In addition, the melting temperature of PLLA would be increased when the crystallinity is improved, which consequently affects the processability of PLLA by reducing the processing window. To reduce the brittleness, PLLA has been blended with polymers and copolymers. ${ }^{\mathbf{1 4 - 1 6}}$ However, an immiscibility-induced macrophase separation between the two components occurring in the blends would deteriorate their mechanical properties. ${ }^{\mathbf{1 4}}$ For example, pure PLA and pure poly( $\varepsilon$-caprolactone) (PCL) have a tensile strength of $c a .53 \mathrm{MPa}$ and $c a .37 \mathrm{MPa}$ respectively, but the addition of PCL causes PLA/PCL blends to have a reduction in their tensile strength at break as their PCL content increases. ${ }^{15}$ In addition, the transparency of PLLA would be reduced when it is blended with other polymers. ${ }^{16}$ Plasticization has also been used to modify the toughness of PLLA. However, its toughness is degraded by the migration of low-molecularweight plasticizers during the storage of the blend. ${ }^{17}$ Besides, the glass transition temperature of the blends is usually lower than that of pristine PLLA, which would reduce its heat distortion resistance. ${ }^{16}$ Consequently, the crystallinity, the heat distortion resistance and the toughness of the PLLA all have to be considered for modifying its properties.

Generally, block copolymers possess the advantages of the properties of their constituent homopolymers and inhibit a macrophase separation between their components. On the 
other hand, block copolymers of various compositions and molecular architectures can be designed and obtained readily. ${ }^{18,19}$ A technique combining ring-opening polymerization (ROP) and atom transfer radical polymerization (ATRP) has been developed to synthesize di/triblock copolymers from lactone and vinyl monomers. ${ }^{20-25}$ Recently, 2,2,2-tribromoethanol ${ }^{26,27}$ and 2,2,2-trichloroethanol (TCE) $)^{28-30}$ have been used as bi-functional initiators to synthesize block copolymers using this technique and can be applied for synthesizing copolymers of LLA and vinyl monomers.

Acrylates and methacrylates are important vinyl ester monomer families. Depending on the nature of the substituent groups, their polymers have various morphological, thermal, and mechanical properties. For example, the glass transition temperature $\left(T_{\mathrm{g}}\right)$ of methacrylate polymers is usually higher than that of acrylate polymers, ${ }^{31}$ and most $\mathrm{P}(\mathrm{M}) \mathrm{A}$ polymers are amorphous. Consequently, $\mathrm{P}(\mathrm{M}) \mathrm{A}$ blocks, when added to PLLA, are expected to modify its heat distortion resistance and its toughness.

The objective of the present study was to explore the possibility of modifying the thermal and crystallinity properties of PLLA by introducing poly(meth)acrylate blocks. Three (meth) acrylate monomers with different substituent groups [methyl methacrylate (MMA), tert-butyl acrylate ( $t$-BA) and 2-ethylhexyl acrylate (2EHA)] were used to study the effects of the (meth) acrylate blocks on the glass transition temperature, crystallinity, thermal stability and microscopic morphology of block copolymers of LLA and (meth)acrylate. The glass transition temperatures of PMMA, PtBA and P2EHA are 115, 40 and $-65{ }^{\circ} \mathrm{C}$ respectively, ${ }^{32-35}$ and it was possible to control the glass transition temperature, the crystallinity and the thermal properties of block copolymers of LLA and (meth)acrylate by changing the chain length and the type of (meth)acrylate blocks. Block copolymers were synthesized by combining ROP of L-lactide and ATRP of (meth)acrylate monomers without intermediate functionalization steps. The effects of PLLA macroinitiators with different molecular weights and (meth)acrylate monomers with different structures on the copolymerization results were investigated by gel permeation chromatography (GPC) measurements. In addition, the effects of the P(M)A blocks on the glass transition, the crystallinity and the thermal stability of the block copolymers were studied by differential scanning calorimetry (DSC) and thermogravimetric analysis (TGA). Furthermore, the microscopic morphology of the block copolymer thin films was examined by atomic force microscopy (AFM) and scanning electron microscopy (SEM).

\section{Experimental details}

\subsection{Materials}

L-Lactide (LLA) ( $\geq 99 \%$, Shenzhen Bright China Industrial Co. Ltd., China), methyl methacrylate (MMA) (AR, Aladdin Reagents Co. Ltd., China), CuCl ( $\geq 97 \%$, Shanghai Chemical Co. Ltd., China) and dimethyl sulfoxide (DMSO) (GR, Aladdin) were purified using a method already described. ${ }^{30}$ tert-Butyl acrylate $(t \mathrm{BA})$ (97\%, Alfa Aesar China Co. Ltd., China) and 2-ethylhexyl acrylate (2EHA) (AR, Aladdin) were used after distillation purification.
$N, N, N^{\prime}, N^{\prime \prime}, N^{\prime \prime}$-Pentamethyldiethylenetriamine (PMDETA) ( $\geq 99 \%$, Sigma-Aldrich Chemie Gmbh, Germany), stannous octanoate $\left(\mathrm{Sn}(\mathrm{Oct})_{2}\right) \quad(\geq 95 \%$, Sigma-Aldrich Japan, Japan), 2,2,2-trichloroethanol (TCE) ( $\geq 99 \%$, Aladdin), tetrahydrofuran, ethanol and chloroform were used as-received.

\subsection{Synthesis of the diblock copolymers via ATRP of (meth) acrylate}

The macroinitiator PLLA-CI was prepared from TCE and LLA following a process already described ${ }^{30}$ (Scheme 1). The diblock copolymers were synthesized via ATRP of the (meth)acrylate monomers using CuCl/PMDETA as a catalyst system and PLLACl as a macroinitiator (Scheme 1). In a typical polymerization, CuCl (1.9 mg, $0.019 \mathrm{mmol})$ and PLLA-Cl (0.51 g) were added to a tailor-made flask and the system was cycled between vacuum and argon three times to remove oxygen. Then, for example, degassed PMDETA (8.40 mg, $0.048 \mathrm{mmol}$ ), $t$ BA (4.97 g, 38.76 $\mathrm{mmol})$, and DMSO $(10 \mathrm{~mL})$ were added. The solution was further deoxygenated by three freeze-pump-thaw cycles and the flask was then placed in an oil bath kept at $80{ }^{\circ} \mathrm{C}$ for 10 hours. After cooling, the reaction mixture was diluted in chloroform, and passed through a neutral alumina column to remove the catalyst. It was then isolated by precipitation in methanol, followed by drying in vacuum, and at last, the copolymer poly(Llactide)- $b$-poly( $t$-butyl acrylate) (PLLA-b-PtBA) was obtained. The same synthetic strategy was used to synthesize the other two copolymers, poly(L-lactide)- $b$-poly(2-ethylhexyl acrylate) (PLLA$\boldsymbol{b}$-P2EHA) and poly(L-lactide)- $b$-poly(methyl methacrylate) (PLLA- $\boldsymbol{b}$-PMMA). Because the viscosity of the system for PLLA- $\boldsymbol{b}$ P2EHA was high when the reaction time was 6 hours, the reaction times for PLLA- $\boldsymbol{b}$-PtBA and PLLA- $\boldsymbol{b}$-P2EHA were controlled to $7 \mathrm{~h}$ and $6 \mathrm{~h}$ respectively. The molecular weights, $M_{\mathrm{n}}$, of the used macroinitiator were between $0.22 \times 10^{4}$ and $9.65 \times 10^{4} \mathrm{~g} \mathrm{~mol}^{-1}$, and the $M_{\mathrm{n}}$ of the obtained copolymers, as well as the compositions for the copolymerization, are shown in Tables 1 and 2 .

\subsection{Analysis and measurements}

The number-average molecular weight $\left(M_{\mathrm{n}}\right)$, weight-average molecular weight $\left(M_{\mathrm{w}}\right)$ and molecular-weight dispersity $\left(\oslash_{\mathrm{M}}=\right.$ $M_{\mathrm{w}} / M_{\mathrm{n}}$ ) of the obtained PLLA-Cl and di-block copolymers were measured by gel permeation chromatography (GPC) analysis on an Agilent 1100 series liquid chromatograph (Agilent Technologies, USA) equipped with a refractive index detector (G 1362 A) and a series of 10000 and $100 \AA$ A pore sizes polydivinylbenzene columns thermostated at $35{ }^{\circ} \mathrm{C}$. Tetrahydrofuran was used as the mobile phase at a flow rate of $1.0 \mathrm{~mL} \mathrm{~min}^{-1}$, and the column calibration was performed with polystyrene standards.

The vacuum-dried samples were dissolved in chloroform, and then the solution was coated on potassium bromide $(\mathrm{KBr})$ plates. FT-IR spectra were recorded on a Nicolet 560 Fourier transform infrared spectrometer (Nicolet Co., USA) with an accumulation of 64 scans in the $400-4000 \mathrm{~cm}^{-1}$ range at a resolution of $0.5 \mathrm{~cm}^{-1}$.

${ }^{1} \mathrm{H}-\mathrm{NMR}$ spectra were measured with a Bruker ARX400 spectrometer (Bruker Corp., Switzerland) at $600 \mathrm{MHz}$ at 


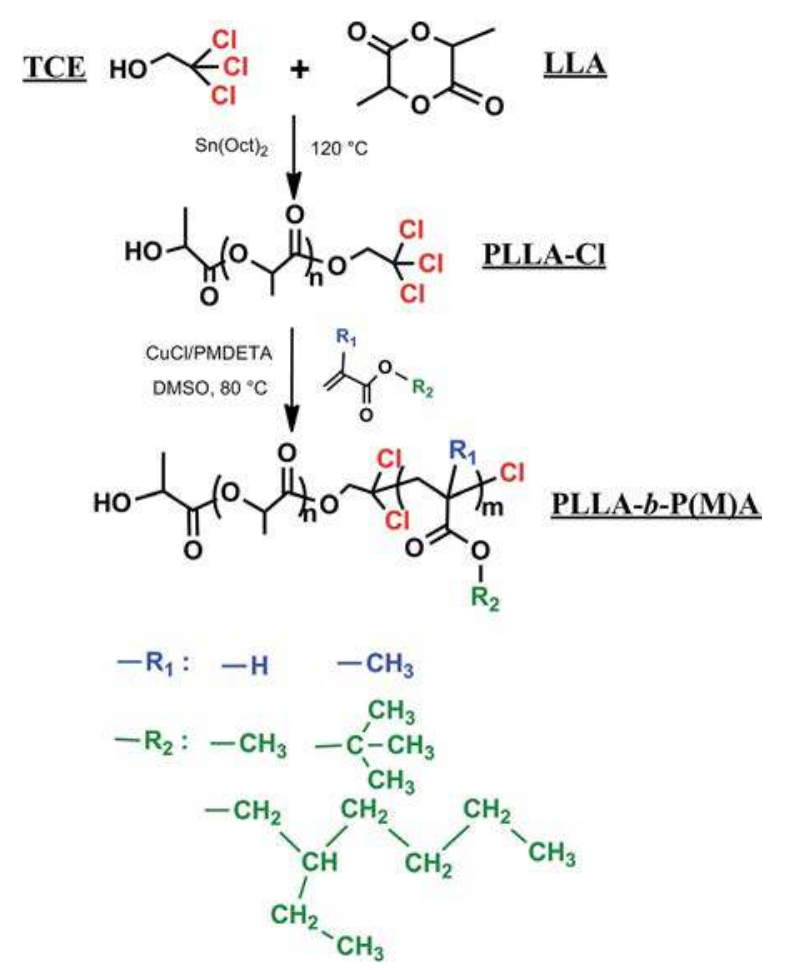

Scheme 1 Synthesis strategy for block copolymers of L-lactide and acrylates.

ambient temperature, using chloroform- $d$ as a solvent and tetramethylsilane (TMS) as an internal chemical shift standard respectively.

DSC was recorded using a Mettler Toledo DSC 1 STAR system (Mettler Toledo Co., Switzerland) under nitrogen purge. The first heating scan was from 0 to $210{ }^{\circ} \mathrm{C}$, and the samples were kept at $210{ }^{\circ} \mathrm{C}$ for $5 \mathrm{~min}$ and then cooled to $0^{\circ} \mathrm{C}$ at a rate of $10^{\circ} \mathrm{C}$ $\min ^{-1}$. Finally, after a delay of $5 \mathrm{~min}$ at $0{ }^{\circ} \mathrm{C}$, the samples were heated back to $210{ }^{\circ} \mathrm{C}$ at the same rate. The glass transition temperature $\left(T_{\mathrm{g}}\right)$ was defined as the midpoint temperature of the transition from the second heating scan.

TGA was performed with a SDT Q600 thermogravimetric analyzer (TA instrument Co., USA) in the range from 30 to 500 ${ }^{\circ} \mathrm{C}$ using a heating rate of $10{ }^{\circ} \mathrm{C} \mathrm{min}^{-1}$ and a steady nitrogen flow of $100 \mathrm{~mL} \mathrm{~min}^{-1}$.

Thin films of block copolymers were deposited by spin coating on freshly cleaved mica wafers. AFM studies were performed on a Nanoscope Multimode SPM with Nanoscope IIIa controller (Veeco Instruments Co., USA) operating in tapping mode and using a silicon cantilever (nominal specified tip radius of 5-10 $\mathrm{nm}$ ) at room temperature to record both height and phase images. Etched silicon tips with a resonance frequency of approximately $263 \mathrm{kHz}$ and a spring constant of about $20-80 \mathrm{~N} \mathrm{~m}^{-1}$ were used.

The surface morphology of thin films was analyzed by using a scanning electron microscope (JSM-5900LV, JEOL Ltd., Japan) operating in secondary electron mode at an acceleration voltage of $20 \mathrm{kV}$. The surfaces of the samples were gold-coated before SEM studies.

\section{Results and discussion}

\subsection{Chemical structure of block copolymers}

As shown in Table 1, the molecular weight of the block copolymers $\boldsymbol{M}_{\mathbf{n}, \mathbf{c o}, \mathbf{G P C}}$ increases compared with that of the relative macroinitiators $\boldsymbol{M}_{\mathbf{n}, \mathbf{i n}}$. For instance, the GPC trace of the copolymer (B-1) showed a monomodal peak at lower retention time without any shoulder compared to that of the relative macroinitiator PLLA-Cl (MI-1) (Fig. 1), indicating that the block copolymers were formed with little evidence of unreacted starting material from the trichloro-terminated macroinitiators. The FT-IR spectrum of diblock copolymer (B-1), together with macroinitiator PLLA-Cl (MI-1) and poly(methyl methacrylate) (PMMA), is illustrated in Fig. 2. The double-peak absorbance at $1760,1731 \mathrm{~cm}^{-1}$ on the curve of IR absorbance of diblock

Table 1 Copolymerization results of MMA, tBA and 2EHA monomers (M) initiated by PLLA-Cl macroinitiators (MI) with different molecular weights using the CuCl/PMDETA catalyst system. [PLLA-Cl]/[CuCl]/[PMDETA] $\left(\mathrm{mol} \mathrm{mol}^{-1}\right)=1: 1: 2.5 ;[\mathrm{M}] /[\mathrm{Ml}]\left(\mathrm{mol} \mathrm{mol}{ }^{-1}\right)=2000: 1$

\begin{tabular}{|c|c|c|c|c|c|c|c|c|c|}
\hline Copolymers & Monomer (M) & Time (h) & $\begin{array}{l}\text { Conversion } \\
(\%)\end{array}$ & $M_{\mathrm{n}, \mathrm{co}, \mathrm{ca}}\left(\times 10^{4}\right)^{a}$ & $M_{\mathrm{n}, \mathrm{co}, \mathrm{GPC}}\left(\times 10^{4}\right)^{b}$ & $\bigoplus_{\mathrm{M}}^{b}$ & $\begin{array}{l}\text { PLLA-Cl } \\
\text { (MI) }\end{array}$ & $M_{\mathrm{n}, \text { in }}\left(\times 10^{4}\right)^{c}$ & $D_{\mathrm{M}}{ }^{c}$ \\
\hline B-1 & MMA & 24 & 55.7 & 11.35 & 22.02 & 1.34 & MI-1 & 0.22 & 1.50 \\
\hline B-3 & MMA & 24 & 84.3 & 17.63 & 16.49 & 1.47 & MI-3 & 0.78 & 1.21 \\
\hline B-4 & MMA & 24 & 51.9 & 11.83 & 9.39 & 1.64 & MI-4 & 1.43 & 1.26 \\
\hline B-5 & MMA & 24 & 39.1 & 11.62 & 10.93 & 1.40 & MI-5 & 3.80 & 1.37 \\
\hline B-8 & MMA & 72 & 50.1 & 12.60 & 12.31 & 1.88 & MI-5 & 3.80 & 1.37 \\
\hline B-9 & $t \mathrm{BA}$ & 7 & 17.1 & 6.97 & 6.57 & 2.09 & MI-5 & 3.80 & 1.37 \\
\hline B-10 & 2EHA & 6 & 45.5 & 19.35 & 13.26 & 2.86 & MI-5 & 3.80 & 1.37 \\
\hline
\end{tabular}

${ }^{a} M_{\mathrm{n}, \text { co,ca }}$ is the calculated molecular weight of the block copolymers, defined by $M_{\mathrm{n}}$ of macroinitiator $+([\mathrm{M}] /[\mathrm{MI}] \times$ molecular weight of monomer $\times$ conversion), the final conversion was calculated from the yield of the obtained polymer. ${ }^{b} M_{\mathrm{n}, \mathrm{co}, \mathrm{GPC}}$ and $\Xi_{\mathrm{M}}$ are the number average molecular weight and molecular-weight dispersity of block copolymers, respectively, obtained from GPC. ${ }^{c} M_{\mathrm{n}, \text { in }}$ and $D_{\mathrm{M}}$ are the number average molecular weight and molecular-weight dispersity of the macroinitiator PLLA-Cl, respectively, obtained from GPC. ${ }^{d}$ The $[\mathrm{M}] /[\mathrm{MI}]\left(\mathrm{mol}\right.$ mol ${ }^{-1}$ ) of B-7 was $500: 1$. 
Table 2 Glass transition temperature and decomposition temperature at $10 \%$ mass loss of copolymers

\begin{tabular}{|c|c|c|c|c|c|c|c|}
\hline Copolymers & $M_{\mathrm{n}, \mathrm{in}}\left(\times 10^{4}\right)^{a}$ & $M_{\mathrm{n}, \mathrm{co}}\left(\times 10^{4}\right)^{b}$ & $\frac{\left(M_{\mathrm{n}, \mathrm{co}}-M_{\mathrm{n}, \mathrm{in}}\right)}{M_{\mathrm{n}, \mathrm{in}}} c$ & $\begin{array}{l}\text { PLLA block length } \\
\text { (number of monomer units) }\end{array}$ & $\begin{array}{l}\mathrm{P}(\mathrm{M}) \mathrm{A} \text { block length } \\
\text { (number of monomer units) }\end{array}$ & $T_{\mathrm{g}}\left({ }^{\circ} \mathrm{C}\right)^{d}$ & $T_{\mathrm{d}}\left({ }^{\circ} \mathrm{C}\right)^{e}$ \\
\hline B-1 & 0.22 & 22.02 & 100.0 & 30 & 2180 & 125.5 & 262 \\
\hline B-2 & 0.55 & 12.72 & 22.2 & 76 & 1217 & 126.0 & 260 \\
\hline B-3 & 0.78 & 16.49 & 20.0 & 108 & 1571 & 120.7 & 256 \\
\hline B-4 & 1.43 & 9.39 & 5.6 & 198 & 796 & 114.6 & 226 \\
\hline B-5 & 3.80 & 10.93 & 1.9 & 527 & 713 & 98.9 & 230 \\
\hline B-6 & 9.65 & 18.06 & 0.9 & 1340 & 841 & 79.9 & 215 \\
\hline B-7 & 3.41 & 5.68 & 0.7 & 473 & 227 & 77.2 & 214 \\
\hline B-8 & 3.80 & 12.31 & 2.2 & 527 & 851 & 103.8 & 228 \\
\hline B-9 & 3.80 & 6.57 & 0.7 & 527 & 216 & 62.6 & 234 \\
\hline B-10 & 3.80 & 13.26 & 2.5 & 527 & 514 & -64.5 & 315 \\
\hline
\end{tabular}

${ }^{a} M_{\mathrm{n}, \mathrm{in}}$ is the number average molecular weight of macroinitiator PLLA-Cl, obtained from GPC. ${ }^{b} M_{\mathrm{n}, \mathrm{co}}$ is the number average molecular weight of copolymers, obtained from GPC. ${ }^{c} \frac{\left(M_{\mathrm{n}, \mathrm{co}}-M_{\mathrm{n}, \mathrm{in}}\right)}{M_{\mathrm{n}, \mathrm{in}}}$ is the ratio of molecular weight of poly(meth)acrylate blocks and PLLA blocks. ${ }^{d} T_{\mathrm{g}}$ is the glass transition temperature of copolymers during the second heating run. ${ }^{e} T_{\mathrm{d}}$ is the decomposition temperature of copolymers at $10 \%$ mass loss.

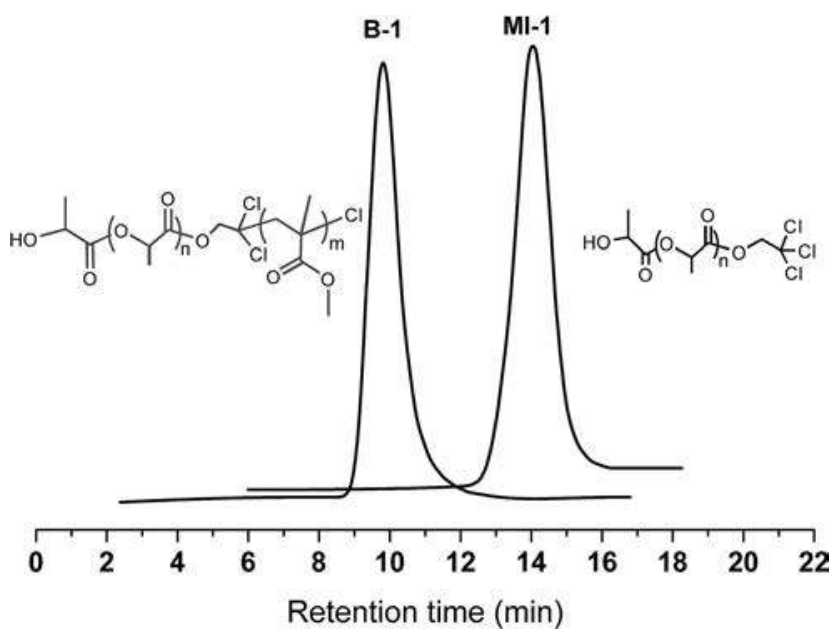

Fig. 1 GPC traces of (a) macroinitiator PLLA-Cl, MI-1, (b) PLLA- $b$ PMMA, B-1.

copolymer (B-1) are characteristic of carbonyl $\mathrm{C}=\mathrm{O}$ stretching in PLLA (1758 $\mathrm{cm}^{-1}$ ) and PMMA $\left(1731 \mathrm{~cm}^{-1}\right)$ chain blocks, respectively. This along with other characteristic vibrational bands due to PLLA and PMMA confirms the presence of the two segments in the diblock copolymers. The structure of the block copolymer is further confirmed by ${ }^{1} \mathrm{H}-\mathrm{NMR}$, revealing resonances correlating to both the PLLA and PMMA blocks. ${ }^{1} \mathrm{H}-\mathrm{NMR}$ $\left[\mathrm{CDCl}_{3}, 600 \mathrm{MHz}\right], \delta[\mathrm{ppm}]: 5.14-5.19$ (q, $\mathrm{CHCH}_{3}$, PLLA segment); 1.57, 1.59 (d, $-\mathrm{CH}_{3}$, PLLA segment); 3.60 (s, $-\mathrm{OCH}_{3}$, PMMA segment); 1.73-2.07 (m, - $\mathrm{CH}_{2}-$, PMMA segment); 0.85, 1.02 (s, $\mathrm{CH}_{3}-\mathrm{C}-$, PMMA segment).

As previously reported, the structure of the block copolymers, PLLA- $\boldsymbol{b}$-PtBA and PLLA- $\boldsymbol{b}$-P2EHA synthesized here, was confirmed by GPC (Table 1), FTIR (Fig. 3 and Table 3 ) and ${ }^{1} \mathrm{H}^{-}$ NMR (Fig. 4 and Table 4). Characteristic bands of the two blocks in the copolymer were observed, indicating that the PLLA-based di-block copolymers were achieved.

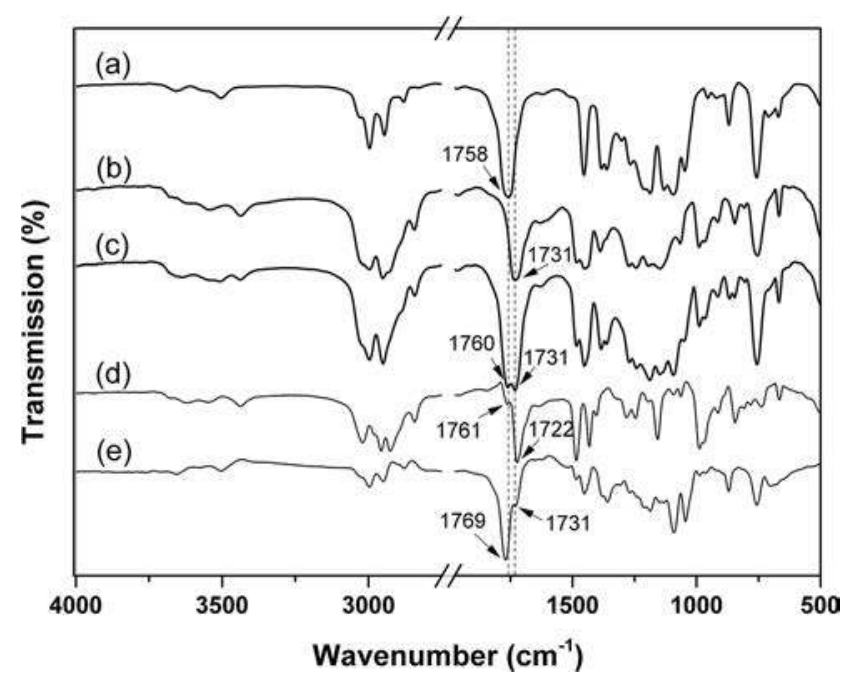

Fig. 2 FTIR spectra of (a) macroinitiator PLLA-Cl, MI-1, (b) PMMA, (c) PLLA- $b$-PMMA, B-1, and the subtracted spectrum: (d) $=(\mathrm{c})-(\mathrm{a}),(\mathrm{e})=$ (c) - (b).

\subsection{Effects of macroinitiators on the copolymerization}

As PLLA can be partially dissolved in non-polar solvents, the synthesis of the copolymers via ATRP of the (meth)acrylate monomers using high-molecular-weight PLLA as a macroinitiator in such solvents becomes problematic. Therefore, a polar solvent, dimethyl sulfoxide (DMSO), was used in our experiments. The dynamic equilibrium and the controllability of the polymerization depend on several reaction factors, such as temperature, activity of the monomer and polarity of the solvent. ${ }^{36}$ In our previous report, ${ }^{30}$ 2,2,2-trichloroethanol was used as a dual initiator to synthesize block copolymers of LLA and methyl methacrylate (MMA) without intermediate steps. It was found that a high monomer concentration and a short reaction time were beneficial to the control of the polymerization process when trichloro-terminated PLLA (PLLA-Cl) was used as a macroinitiator. In the present work, the effect of 


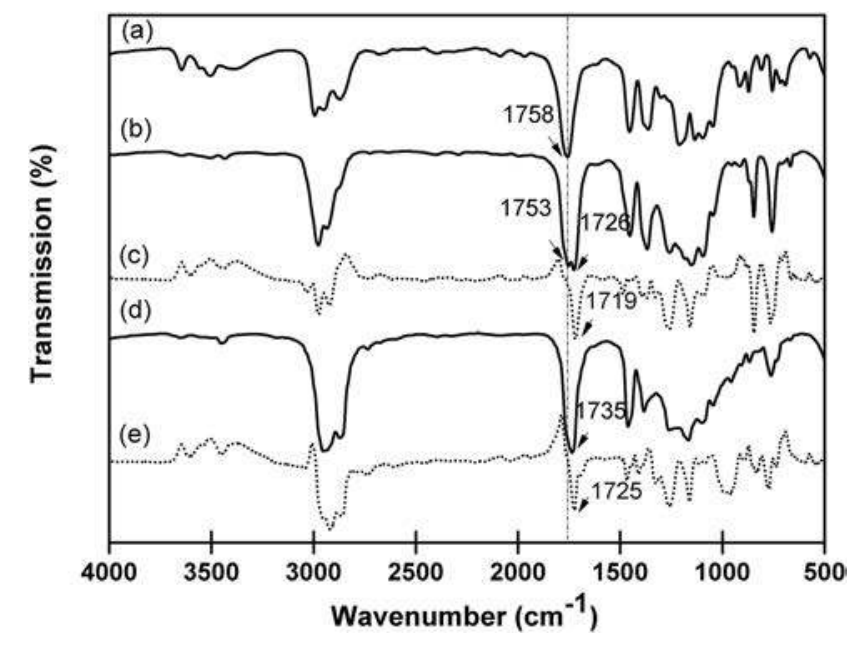

Fig. 3 FTIR spectra of (a) macroinitiator PLLA-Cl, (b) PLLA- $b$-PtBA, B9, and the subtracted spectrum (c) = (b) - (a), (d) PLLA-b-P2EHA, B-10, and the subtracted spectrum $(e)=(d)-(a)$.

Table 3 Characteristic bands in infrared spectra of PLLA- $b-P t B A$ and PLLA- $b-$ P2EHA

\begin{tabular}{ll}
\hline Wavenumber $\left(\mathrm{cm}^{-1}\right)$ & Assignments \\
\hline PLLA- $b$-PtBA & \\
2978,2936 & $\nu_{(\mathrm{C}-\mathrm{H})}$, PLLA and PtBA \\
1753 & $\nu_{(\mathrm{C}=\mathrm{O})}$, PLLA \\
1726 & $\nu_{(\mathrm{C}=\mathrm{O})}$, PtBA \\
1453 & $\delta_{(\mathrm{C}-\mathrm{H})}$, PLLA and PtBA \\
1388,1367 & $\delta_{(\mathrm{C}-\mathrm{H})}$, P BA \\
$1257,1183,1150,1094$ & $\nu_{(\mathrm{C}-\mathrm{O}-\mathrm{C})}$, PLLA and PtBA \\
846 & $\nu_{(\mathrm{C}-\mathrm{COO})}$, PLLA \\
757 & $\delta_{(\mathrm{C}=\mathrm{O})}$, PLLA \\
& \\
PLLA- $b$-P2EHA & \\
$2959,2925,2865$ & $\nu_{(\mathrm{C}-\mathrm{H})}$, PLLA and P2EHA \\
1735 & $\nu_{(\mathrm{C}=\mathrm{O})}$, P2EHA \\
1460,1382 & $\delta_{(\mathrm{C}-\mathrm{H})}$, PLLA and P2EHA \\
$1255,1213,1165,1094$ & $\nu_{(\mathrm{C}-\mathrm{O}-\mathrm{C})}$, PLLA and P2EHA \\
867 & $\nu_{(\mathrm{C}-\mathrm{COO})}$, PLLA \\
762 & $\delta_{(\mathrm{C}=\mathrm{O})}$, PLLA \\
\hline
\end{tabular}

molecular weight of the macroinitiator on the copolymerization was investigated. As shown in Table 1, the molecular weight $M_{\mathrm{n}}$ of the macroinitiator had a significant effect on the PMMA block length of the copolymers as determined from the difference in molecular weight of the PLLA-Cl and the copolymers. For instance, under identical experimental conditions, the number of MMA chain units of the PMMA blocks of B-1 $\left(M_{\mathrm{n}}=\right.$ $\left.22.02 \times 10^{4} \mathrm{~g} \mathrm{~mol}^{-1}\right)$ was $c a .2180$ with the corresponding macroinitiator MI-1 $\left(M_{\mathrm{n}}=0.22 \times 10^{4} \mathrm{~g} \mathrm{~mol}^{-1}\right)$, and the number of MMA chain units of copolymer B-6 $\left(M_{\mathrm{n}}=18.06 \times 10^{4} \mathrm{~g}\right.$ $\left.\mathrm{mol}^{-1}\right)$ was reduced to $c a .840$ when MI-6 $\left(M_{\mathrm{n}}=9.65 \times 10^{4} \mathrm{~g}\right.$ $\mathrm{mol}^{-1}$ ) was used as a macroinitiator. This variation can be attributed to the decrease in solubility of PLLA-Cl in DMSO and to the increase in viscosity of the system due to the increase of the molecular weight of the macroinitiator. The increase in viscosity reduce the mobility of the reactive polymer chains, the diffusion process of the monomers and the activity of macroinitiator, which results in slower chain propagation. The $D_{\mathrm{M}}$ of the block copolymers increased when the $M_{\mathrm{n}}$ of the macroinitiator increased, for example, the $D_{\mathrm{M}}$ of $\mathbf{B}-\mathbf{1}$ is 1.34 and that of B-6 is 1.87. It is deduced that the "atom transfer step" of the ATRP process was influenced when the diffusion process of the monomers and the activity of macroinitiator reduced due to the higher molecular weight of the macroinitiator.

\subsection{Effects of (meth)acrylate monomers on the copolymerization}

As shown in Table 1, when the macroinitiator PLLA-Cl with the same molecular weight was used, the molecular weight of PLLAb-P2EHA (B-10) within a shorter reaction time was higher than that of the comparable PLLA-b-PMMA (B-5) and PLLA-b-PtBA (B9). It could be concluded that the reaction rate of ATRP of $2 \mathrm{EHA}$ was higher than that of MMA and $t \mathrm{BA}$. This may be ascribed to the effects of the long chain alkyl groups of 2EHA. The $D_{\mathrm{M}}$ of PLLA- $\boldsymbol{b}$-PtBA and PLLA- $\boldsymbol{b}$-P2EHA were noticeably larger than that of the PLLA- $\boldsymbol{b}$-PMMA (B-5) due to higher rate constants of propagation for $t \mathrm{BA}$ and 2EHA. The atom transfer step is the key elementary reaction responsible for the uniform growth of the polymeric chains in an ATRP process. The atom transfer equilibrium and the $D_{\mathrm{M}}$ of polymers relate to the rate constants of propagation of monomers, indicating that the chemical structure of the (meth)acrylate monomers had a significant influence on the ATRP process.

The molecular weight of the block copolymers was determined by ${ }^{1} \mathrm{H}-\mathrm{NMR}$ analysis. For example, for copolymer PLLA- $\boldsymbol{b}$ P2EHA, the repeat unit ratio of the PLLA blocks to P2EHA blocks was calculated to be $1: 3.31$ by comparing the integrated intensities of peak a $\left(1 \mathrm{H}, \mathrm{OC}^{\mathrm{H}} \mathrm{CH}_{3} \mathrm{CO}\right.$, PLLA segments) and peak e $\left(2 \mathrm{H},-\mathrm{OCH}_{2}-\mathrm{CH}-\right.$, P2EHA segments) (Fig. 4). The molecular weight of the block copolymer (B-10) from the ${ }^{1} \mathrm{H}^{-}$ NMR results $\left(M_{\mathrm{n}, \mathrm{NMR}}\right)$ was determined to be $20.87 \times 10^{4} \mathrm{~g}$ $\mathrm{mol}^{-1}$ based on the starting PLLA (MI-5, $M_{\mathrm{n}, \mathrm{GPC}}=3.80 \times 10^{4} \mathrm{~g}$ $\left.\mathrm{mol}^{-1}\right)$. This value is close to the calculated value $\left(19.35 \times 10^{4} \mathrm{~g}\right.$ $\mathrm{mol}^{-1}$ ) of the molecular weight on the basis of the monomer conversion. However, the molecular weight from $\operatorname{GPC}\left(M_{\mathrm{n}, \mathrm{GPC}}=\right.$ $13.26 \times 10^{4} \mathrm{~g} \mathrm{~mol}^{-1}$ ) was obviously lower than the values mentioned above. To explain the difference, we can note that several factors would influence the GPC measurement results. First, the $M_{\mathrm{w}}$ of the polymer is determined by the column calibration performed with polystyrene standards, which could affect the accuracy. In addition, the solubility of polymers in the solvents used and their interaction may also affect the GPC results. Therefore, we were not able to determine the exact molecular weight of the block copolymers by GPC, though the values can still be used to describe the molecular weight of the polymers.

\subsection{Glass transition temperature and crystallinity of block copolymers}

The glass transition temperature $\left(T_{\mathrm{g}}\right)$ of PMMA is reported to be in the $105-125{ }^{\circ} \mathrm{C}$ range,,$^{32,33}$ which is higher than that of PLLA. No conspicuous melting and recrystallization peaks for low- 

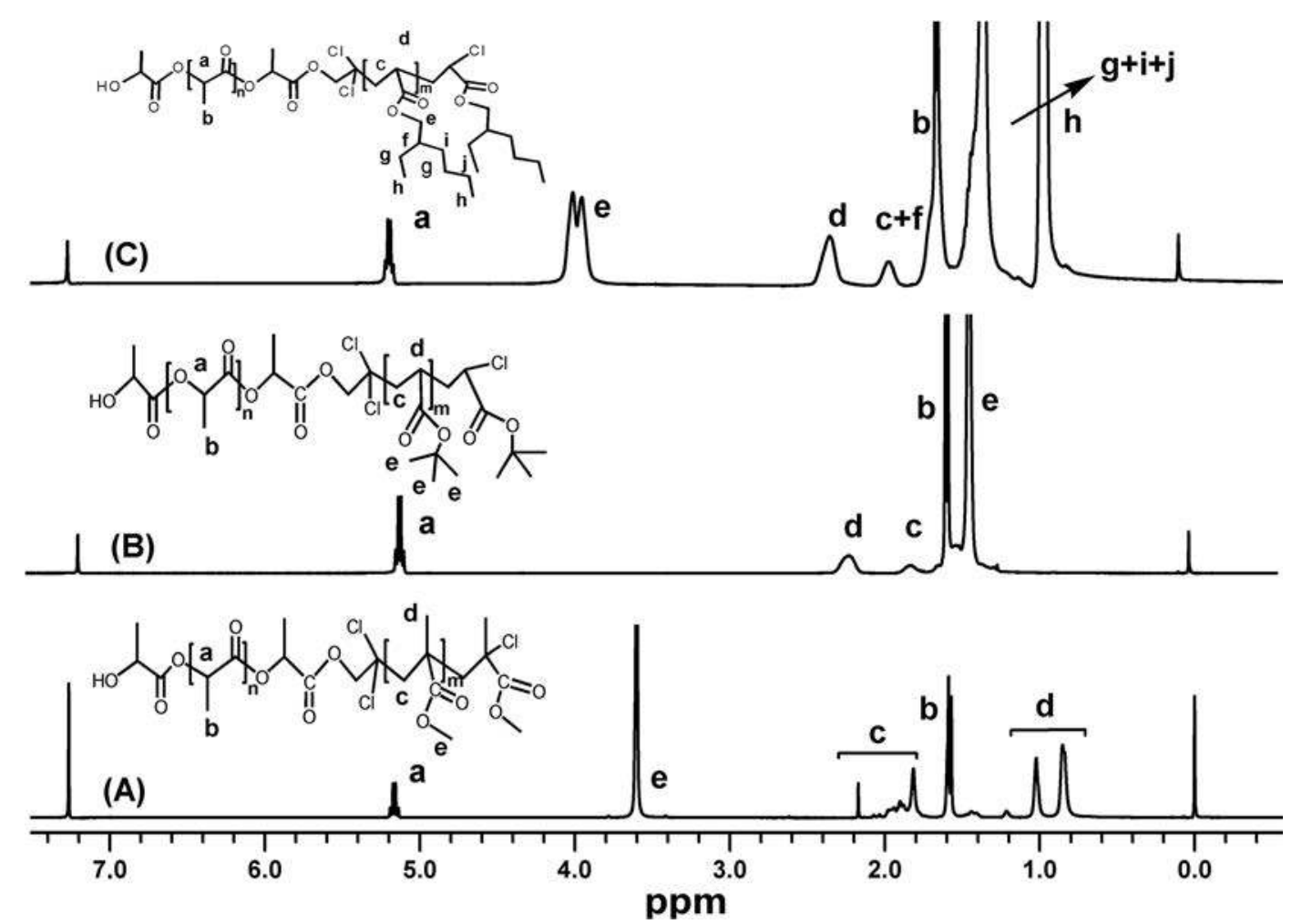

Fig. 4 Comparison of ${ }^{1} \mathrm{H}-\mathrm{NMR}$ spectra for copolymers (A) PLLA- $b$-PMMA, B-5, (B) PLLA- $b-P t B A, B-9$, and (C) PLLA-b-P2EHA, B-10.

Table $4{ }^{1} \mathrm{H}$-NMR chemical shifts of PLLA- $b$-PtBA and PLLA- $b-P 2 E H A$

\begin{tabular}{|c|c|}
\hline Chemical shift (ppm) & Assignments \\
\hline \multicolumn{2}{|l|}{ PLLA- $b$-PtBA } \\
\hline $5.14-5.19$ & $\mathrm{q},-\mathrm{CHCH}_{3}$, PLLA \\
\hline $1.57,1.59$ & $\mathrm{~d},-\mathrm{CH}_{3}$, PLLA \\
\hline 2.22 & $\mathrm{~m},-\mathrm{CH}_{2}-\underline{C H}-, \mathrm{P} t \mathrm{BA}$ \\
\hline 1.63 & $\mathrm{~m},-\underline{\mathrm{CH}_{2}}-\mathrm{CH}-, \mathrm{P} t \mathrm{BA}$ \\
\hline 1.43 & $\mathrm{~s},-\mathrm{O}-\left(\underline{\left(\mathrm{CH}_{3}\right.}\right)_{3}, \mathrm{P} t \mathrm{BA}$ \\
\hline \multicolumn{2}{|l|}{ PLLA- $b$-P2EHA } \\
\hline $5.13-5.18$ & $\mathrm{q}, \underline{\mathrm{CH}} \mathrm{CH}_{3}$, PLLA \\
\hline $1.57,1.59$ & $\mathrm{~d},-\mathrm{CH}_{3}$, PLLA \\
\hline $1.88-1.90$ & $\begin{array}{l}\mathrm{m},-\underline{\mathrm{CH}_{2}}-\mathrm{CH}-\text { of backbone, }-\underline{\mathrm{CH}}\left(\mathrm{CH}_{2}\right)-\mathrm{CH}_{2}, \\
\text { P2EHA }\end{array}$ \\
\hline 2.28 & $\mathrm{~m},-\mathrm{CH}_{2}-\underline{\mathrm{CH}}-$ of backbone, P2EHA \\
\hline $3.89,3.95$ & $\mathrm{~d},-\mathrm{O}-\overline{\mathrm{CH}_{2}}-\mathrm{CH}-, \mathrm{P} 2 \mathrm{EHA}$ \\
\hline $1.27-1.37$ & $\begin{array}{l}\mathrm{m},-\mathrm{CH}-\mathrm{CH}_{2}-\mathrm{CH}_{3},-\mathrm{CH}-\mathrm{CH}_{2}-\mathrm{CH}_{2}-\mathrm{CH}_{2}- \\
\mathrm{CH}_{3},-\mathrm{CH}-\mathrm{CH}_{2}-\mathrm{CH}_{2}-\mathrm{CH}_{2}-\mathrm{CH}_{3},-\mathrm{CH}-\mathrm{CH}_{2}- \\
\mathrm{CH}_{2}-\mathrm{CH}_{2}-\mathrm{CH}_{3}, \text { P2EHA }\end{array}$ \\
\hline $0.87-0.89$ & $\mathrm{~m},-\overline{\mathrm{CH}_{2}-\mathrm{CH}_{3}}$, P2EHA \\
\hline
\end{tabular}

molecular-weight PLLA blocks were observed during the first heating scans of the copolymers PLLA-b-PMMA (Fig. 5a). It means that the introduction of the PMMA blocks affected the chain organization of PLLA blocks in the copolymers and inhibited its crystallization. However, when the molecular weight of the PLLA blocks was as high as $9.65 \times 10^{4} \mathrm{~g} \mathrm{~mol}^{-1}$ and the ratio of the molecular weights of the PMMA/PLLA blocks decreased to 0.9 (B-6), the copolymer exhibited a doublemelting behavior on the first heating scan with a lowtemperature melting temperature $\left(T_{\mathrm{m}}\right)$ peak at $158{ }^{\circ} \mathrm{C}$ and a high-temperature $T_{\mathrm{m}}$ peak at $173{ }^{\circ} \mathrm{C}$ (Fig. 5a). The lowtemperature peak can be ascribed to the melting of the crystallites, formed during the preparation of the samples, before DSC heating and the high-temperature peak to the crystallites formed by a melting-recrystallization-melting mechanism during the heating process. ${ }^{37}$

Different heat histories have impact on the thermal properties of polymer samples. A second heating scan was employed to investigate the glass transition temperature and crystallinity of the copolymers after a heating-cooling cycle (to eliminate the heat history). Compatibilizers are usually used to avoid macrophase separation in polymer blends due to the immiscibility between the two components. ${ }^{\mathbf{1 4}}$ However, for block copolymers, the macrophase separation is limited by the linkage of covalent bonds between the polymer blocks. Only one $T_{\mathrm{g}}$ was observed on each curve of all the copolymer samples during the cooling scans and there were no crystallization peaks. This result indicates that the crystallization of PLLA blocks was restrained by the PMMA blocks. Similarly, only one glass transition temperature $T_{\mathrm{g}}$, without crystallization or melting peak, was observed in the second heating scans (Fig. 5b and 6), even for the sample B-6 with a PMMA/PLLA ratio of 0.9 (Table 2). Therefore, the copolymers failed to crystallize and no macrophase separation occurred between the PLLA and PMMA blocks. The presence of the amorphous phase is necessary to reduce the brittleness of PLLA, and the absence of macrophase separation can play 


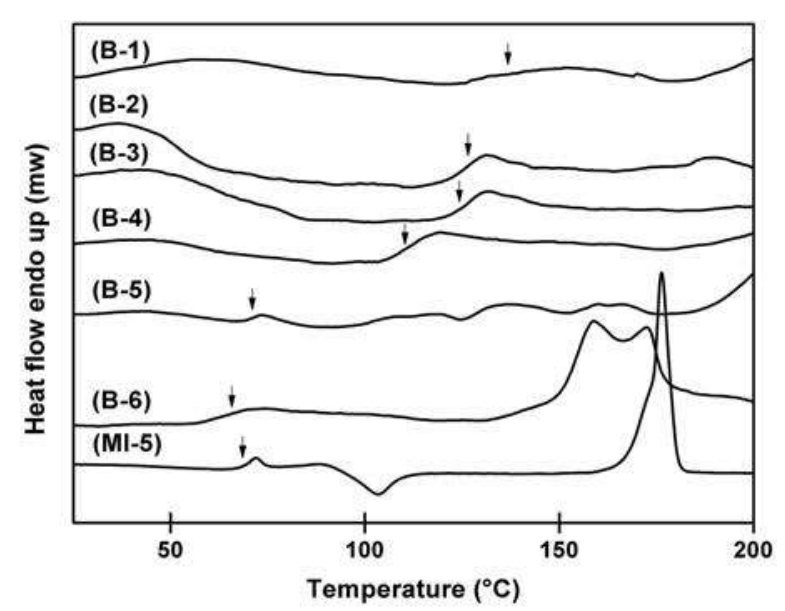

(a)

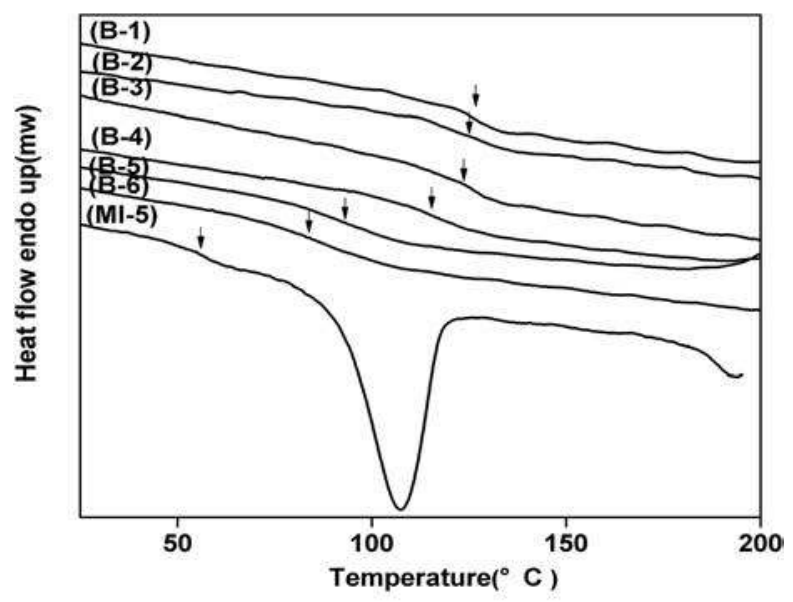

(b)

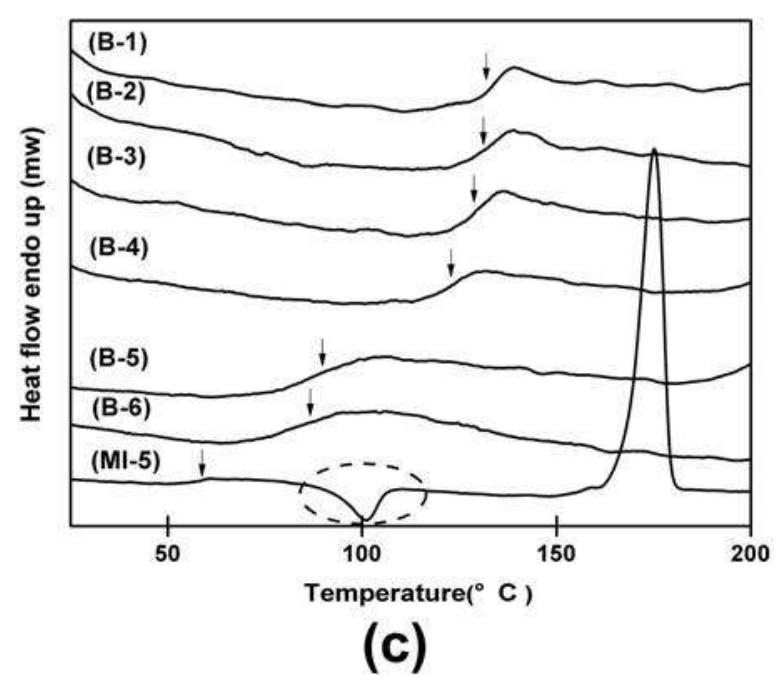

Fig. 5 The first heating (a), the cooling (b) and second heating (c) scans of PLLA- $b$-PMMA copolymers and macroinitiator PLLA-Cl. The arrows indicate the glass transition temperatures.

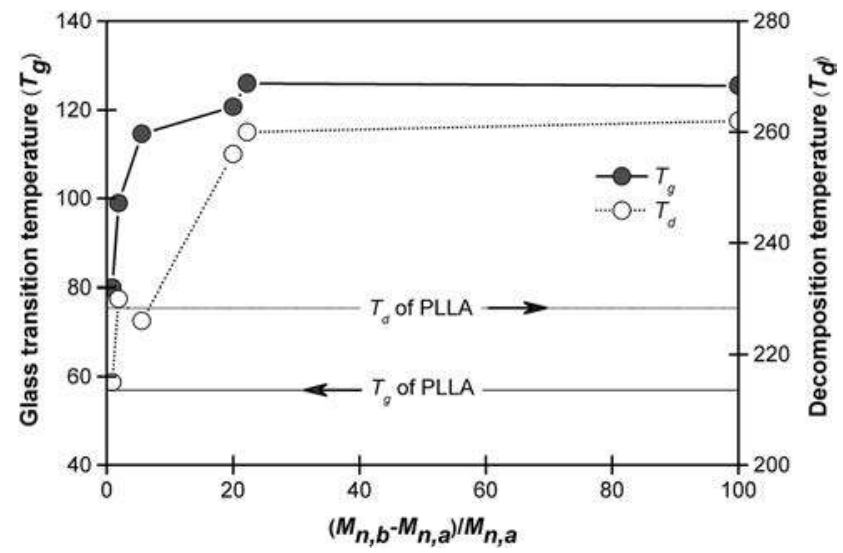

Fig. 6 Plots of glass transition temperature $\left(T_{\mathrm{g}}\right)$ and decomposition temperature $\left(T_{d}\right)$ vs. the ratio of the molecular weights of the PMMA blocks to the PLLA blocks $\left(M_{n, b}-M_{n, a}\right) / M_{n, a}$ "a" stands for the macroinitiator and "b" stands for the copolymer.

a beneficial role on the mechanical properties. When the ratio of the size of the PMMA/PLLA blocks in the copolymers increased from 0.9 (B-6) to 100 (B-1), the $T_{\mathrm{g}}$ of the copolymers increased and gradually shifted to that of pure PMMA (Fig. 6 and Table 2). Therefore, the $T_{\mathrm{g}}$ of the block copolymers can be controlled by changing the chain length of the PMMA blocks as well as the ratio of the size of the PMMA/PLLA blocks. For example, the $T_{\mathrm{g}}$ of copolymer B-6 was $79.9{ }^{\circ} \mathrm{C}$ when the ratio of the size of the PMMA/PLLA blocks was 0.9 , and increased to $125.5^{\circ} \mathrm{C}$ when the ratio equaled $100(\mathbf{B}-1)$. When $T_{\mathrm{g}}$ increased, the heat distortion resistance of the copolymers was enhanced as compared with that of PLLA. In addition, the introduction of PMMA blocks restrained the arrangement and the crystallization process of PLLA, and the copolymers became amorphous.

To tune the $T_{\mathrm{g}}$ of copolymers to a lower value, two polyacrylates of low $T_{\mathrm{g}}, \mathrm{P} t \mathrm{BA}$ and P2EHA, were introduced into the block copolymers. The glass transition temperature and the crystallinity of the block copolymers PLLA- $\boldsymbol{b}$-PtBA and PLLA- $\boldsymbol{b}$ P2EHA were also investigated by DSC and were compared with that of the PLLA- $\boldsymbol{b}$-PMMA of similar $M_{\mathrm{n}}$ and $D_{\mathrm{M}}$. Considering PLLA- $b$-PtBA first, Fig. 7 a shows that both PLLA-b-PtBA (B-9) and PLLA-b-PMMA (B-7) had asymmetric double melting peaks during the first heating scans. The intensity areas of the hightemperature melting peaks (corresponding to the melting of recrystallized PLLA formed during the heating scan) were larger than those of the low-temperature melting peaks, suggesting that the crystallization of PLLA mainly occurred during the heating process. For the second heating scans, the melting peaks of the copolymers almost disappeared except for a weak peak at $173.8^{\circ} \mathrm{C}$ for PLLA- $\boldsymbol{b}$-PtBA, which is indicative of a lesser effect of the PtBA blocks in PLLA-b-PtBA on the crystallization of PLLA compared with PMMA blocks in PLLA-b-PMMA. Only one glass transition temperature $T_{\mathrm{g}}$ was observed in the heating scans, indicating that there was no macrophase separation in the copolymer matrix. Though the two blocks are not miscible, they are linked with covalent bonds, leading to microphase separation. The $T_{\mathrm{g}}$ of PLLA- $\boldsymbol{b}$-P $\mathbf{t} \mathbf{B A}$ measured on the first heating 


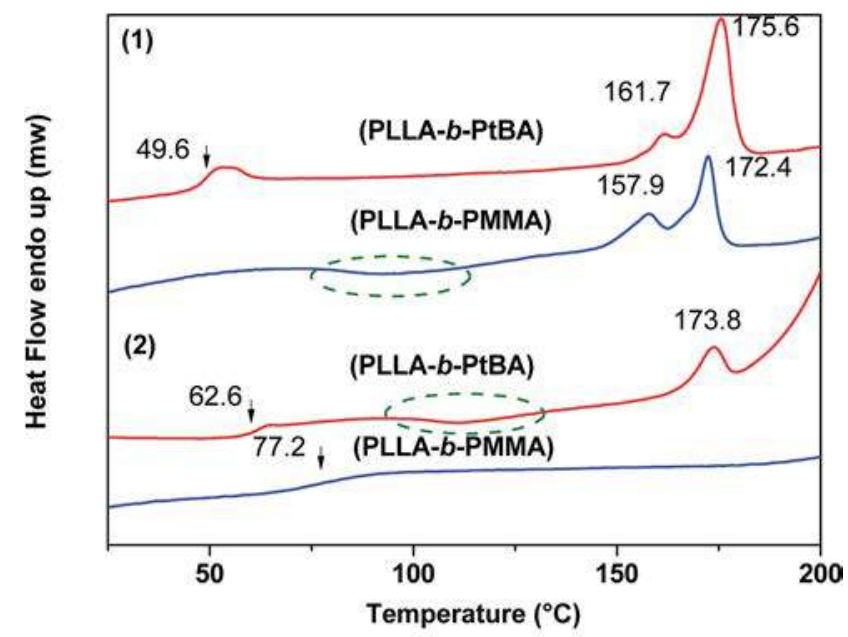

(a)

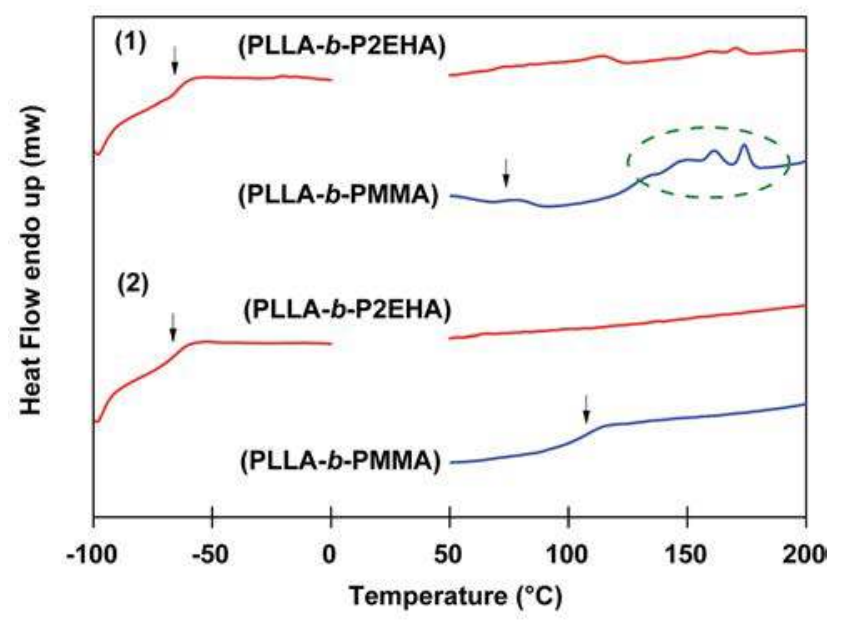

(b)

Fig. 7 The first (1) and second (2) DSC heating scans of copolymers (a) PLLA- $b$-PMMA, B-7, and PLLA- $b-P t B A, B-9$; (b) PLLA- $b-P M M A, B-8$ and PLLA- $b-\mathrm{P} 2 \mathrm{EHA}, \mathrm{B}-10$. The arrows indicate the glass transition temperatures.

scan $\left(49.6{ }^{\circ} \mathrm{C}\right)$ was higher than that of pure PtBA $\left(\sim 40{ }^{\circ} \mathrm{C}\right)^{34}$ but lower than that of pure PLLA $\left(\sim 65^{\circ} \mathrm{C}\right)$. For the second heating scans, the $T_{\mathrm{g}}$ of PLLA- $\boldsymbol{b}$-PtBA $\left(62.6^{\circ} \mathrm{C}\right)$ was lower than that of pure PLLA, and the $T_{\mathrm{g}}$ of PLLA- $\boldsymbol{b}$-PMMA $\left(77.2^{\circ} \mathrm{C}\right)$ was higher than that of pure PLLA, indicating that the $T_{\mathrm{g}}$ of the block copolymers can also be tuned by changing the polyacrylate blocks. The endothermic peak in the glass transition region of the first heating scan of PLLA- $\boldsymbol{b}$-PtBA can be explained in terms of thermal history effects. As for glassy polymer samples quenched from melt to temperatures below $T_{\mathrm{g}}$, the sub- $T_{\mathrm{g}}$ annealing led to physical aging with new cohesional entanglements being formed. An endothermic process was necessary to disengage the cohesional entanglements during the heating scan, and an endothermic peak was observed in the DSC curve. Fig. 7b shows the DSC curves of PLLA- $b$-P2EHA (B-10) and PLLAb-PMMA (B-8). During the first heating scan, the melting peaks of the copolymers nearly disappeared, especially for PLLA- $\boldsymbol{b}$ -
P2EHA, indicating that the crystallization of the PLLA blocks was strongly inhibited. Multi-melting peaks are observed on the first heating scan of B-8, and it can be explained by the multicrystallization of PLLA blocks in the copolymer. The crystallization of the PLLA blocks in the copolymers was inhibited, thus the PLLA blocks could partly crystallize during the preparation and new crystallites could also formed during the storage, and a melting-recrystallization-melting process could occur during the heating scan. For the second heating runs, the $T_{\mathrm{g}}$ of the copolymers, PLLA- $\boldsymbol{b}$-P2EHA (B-10) and PLLA- $\boldsymbol{b}$-PMMA (B-8), were observed at $-64.5{ }^{\circ} \mathrm{C}$ and $103.8^{\circ} \mathrm{C}$ respectively, which are close to that of pure P2EHA $\left(-65.8^{\circ} \mathrm{C}\right)^{35}$ and PMMA (105-125 ${ }^{\circ} \mathrm{C}$ ). Polymers having a low $T_{\mathrm{g}}$ are potentially useful as elastomeric or adhesive materials at room temperature. Theoretically, the $T_{\mathrm{g}}$ of PLLA- $\boldsymbol{b}$-P2EHA could be adjusted over a wide temperature range, from the $T_{\mathrm{g}}$ of P2EHA $-65.8{ }^{\circ} \mathrm{C}$ to that of pure PLLA $65^{\circ} \mathrm{C}$ for different applications, by changing the ratio of PLLA/P2EHA blocks. In summary, the $T_{\mathrm{g}}$ of the copolymers can be modified by using various acrylate monomers for the copolymerization. Therefore, we deduce that the toughness of PLLA should be able to be modified by copolymerization approach.

\subsection{Thermal stability of the block copolymers}

Polylactide is a representative biodegradable polymer and is prone to degradation due to moisture, heat, UV-light, etc. The thermal stabilities of the poly(meth)acrylates are better than that of PLLA because of the presence of carbon-carbon bonds in the backbone of the poly(meth)acrylate chains. It was, therefore, expected that the thermal stability of copolymers could be improved by increasing the poly(meth)acrylate content. Fig. 8 shows the TGA and DTG curves of the copolymers PLLA- $\boldsymbol{b}$ PMMA containing PMMA blocks of different chain lengths. The decomposition temperature $\left(T_{\mathrm{d}}\right)$ of the copolymers was defined as the temperature at $10 \%$ mass loss on the TGA curves. The $T_{\mathrm{d}}$ of the copolymers was rapidly improved as the ratio of PMMA/ PLLA blocks increased (Fig. 6). For example, the $T_{\mathrm{d}}$ of the copolymer B-6 (the ratio of PMMA/PLLA block size was $0.9: 1$ ) was $215{ }^{\circ} \mathrm{C}$, and the $T_{\mathrm{d}}$ of the copolymer B-2 (the ratio of PMMA/ PLLA block size was $22.2: 1$ ) increased to $260{ }^{\circ} \mathrm{C}$, while that of the copolymer B-1 (the ratio of PMMA/PLLA block size was $100: 1$ ) was $262{ }^{\circ} \mathrm{C}$, close to that of $\mathbf{B}-2$. For the free radical polymeric PMMA, there are two degradation models, the endchain scission and the random chain breaking. The thermal decomposition of the block copolymers PLLA- $\boldsymbol{b}$-PMMA was a three-step process (Fig. 8b) For example, the TGA curve of B-5 showed three decomposition rate peak temperatures at 207, 287 , and $372{ }^{\circ} \mathrm{C}$. The first and third weight loss steps were due to the degradation of the PLLA and PMMA blocks, and the second weight loss step was assigned to the end-chain scission of the PMMA blocks. Since the $T_{\mathrm{m}}$ and $T_{\mathrm{d}}$ of PLLA are at $c a .175^{\circ} \mathrm{C}$ and $227{ }^{\circ} \mathrm{C}$ respectively, the heat processing window would still be narrow for PLLA- $\boldsymbol{b}$-PMMA copolymers.

Fig. 9a and b show the TGA and DTG curves of copolymers PLLA- $\boldsymbol{b}$-PtBA and PLLA- $\boldsymbol{b}$-P2EHA, respectively, relative to that of the corresponding PLLA-b-PMMA. For PLLA-b-PtBA (Fig. 9a), 


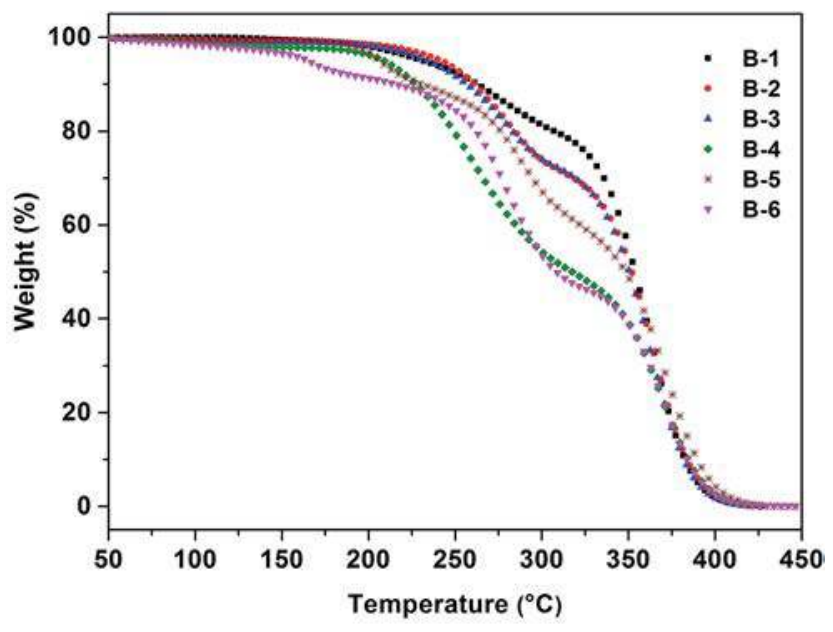

(a)

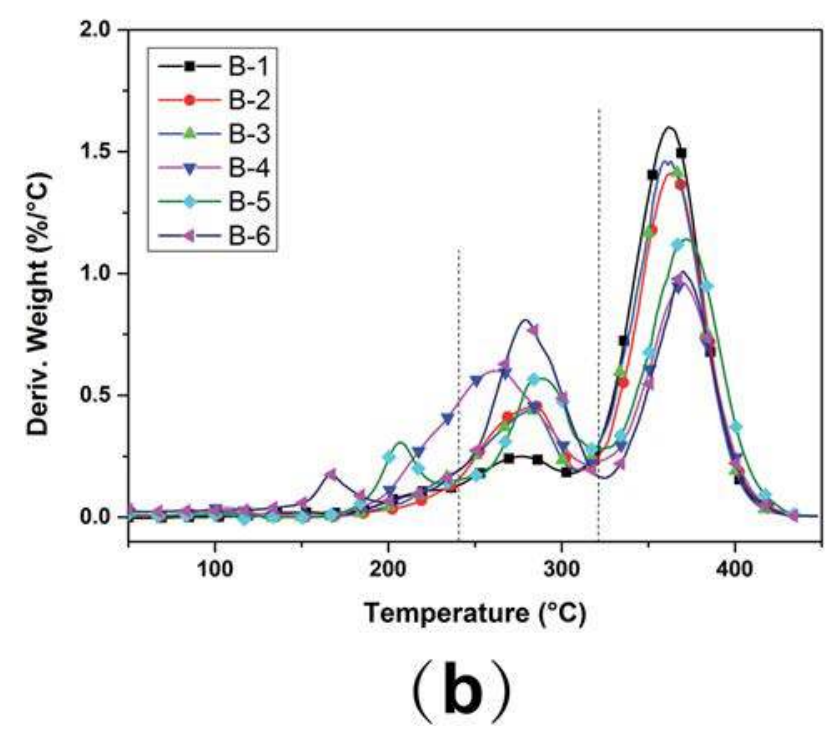

Fig. 8 Thermal gravimetric curves of PLLA- $b$-PMMA copolymers B-1, B-2, B-3, B-4, B-5 and B-6.

two decomposition stages were observed, and the $T_{\mathrm{d}}$ of PLLA- $\boldsymbol{b}$ PtBA was slightly higher than that of PLLA- $\boldsymbol{b}$-PMMA (B-7, Table 2). The first distinct decomposition of PLLA- $\boldsymbol{b}$-PtBA between 210 and $250{ }^{\circ} \mathrm{C}$ with a peak at $238{ }^{\circ} \mathrm{C}$ is generally interpreted as a decomposition of the tert-butyl groups in the PtBA blocks. ${ }^{38}$ The intra and/or intermolecular condensation reactions, elimination of $\mathrm{H}_{2} \mathrm{O}$ and generation of anhydride units, evolution of $\mathrm{CO}_{2}$ and $\mathrm{CO}$ yielding unsaturated hydrocarbon linkages, and the degradation of unsaturated hydrocarbon chains of PtBA blocks may contribute to the second decomposition stage. The decomposition of PLLA also contributes to the two stages. The thermal stability of copolymer PLLA- $\boldsymbol{b}$-P2EHA was enhanced as the decomposition temperature at $10 \%$ mass loss of PLLA- $\boldsymbol{b}$ P2EHA (Fig. 9b) was $315{ }^{\circ} \mathrm{C}$ as compared with that of PLLA- $\boldsymbol{b}$ PMMA (B-8, $\left.228{ }^{\circ} \mathrm{C}\right)$ of similar compositions. In addition, the DTG curves showed that the fastest decomposition rate of PLLAb-P2EHA was observed at $395{ }^{\circ} \mathrm{C}$, which was also higher than

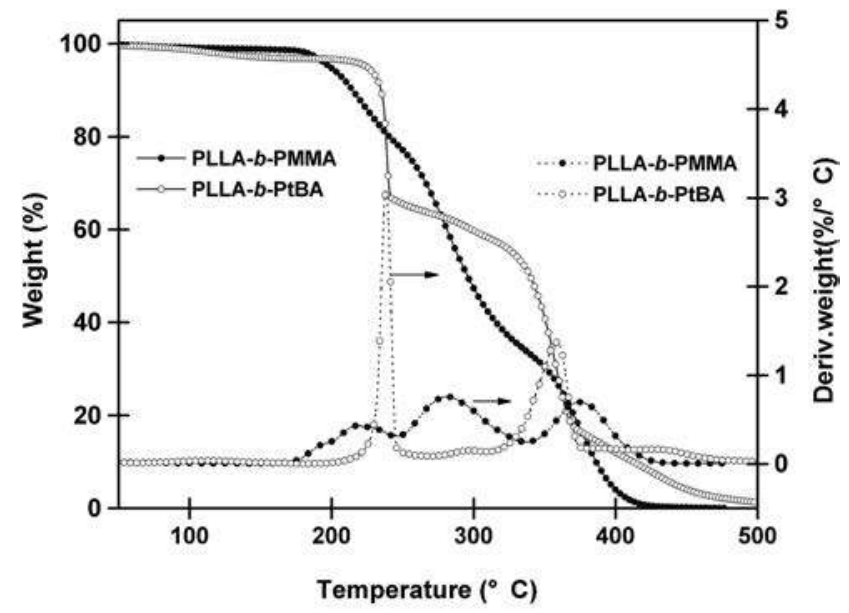

(a)

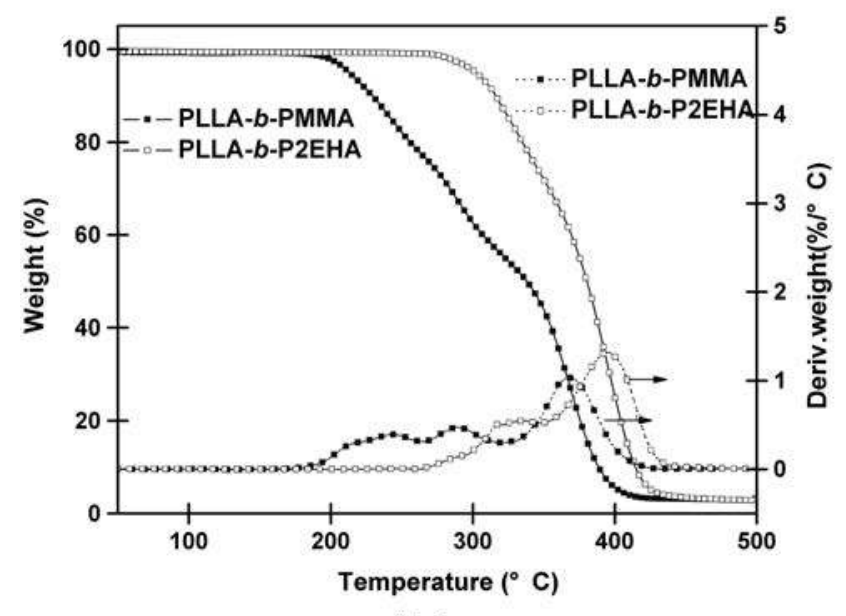

(b)

Fig. 9 Thermal gravimetric curves of copolymers (a) PLLA- $b$-PMMA, B-7 and PLLA- $b$-PtBA, B-9; (b) PLLA- $b-$ PMMA, B-8 and PLLA- $b-$ P2EHA, B-10.

that of PLLA- $\boldsymbol{b}$-PMMA (B-8, $\left.368{ }^{\circ} \mathrm{C}\right)$. The results revealed that PLLA- $\boldsymbol{b}$-P2EHA had a better thermal stability than that of PLLAb-PMMA having similar composition ratio. Generally, the polymers with the lower $T_{\mathrm{g}}$, the lower molecular weight, the lower crystallinity, the wider molecular-weight dispersity have less heat distortion resistance. PLLA-b-PMMA copolymers can perform a better heat distortion resistance than PLLA- $\boldsymbol{b}$-PtBA and PLLA- $\boldsymbol{b}$-P2EHA, because PLLA- $\boldsymbol{b}$-PMMA copolymers have higher $T_{\mathrm{g}}$. However, the influence of the PtBA and P2EHA blocks with different block lengths on the diblock copolymers deserve investigations.

\subsection{Microscopic morphology of the block copolymers}

In contrast to the homopolymers, block copolymers consist of chemically distinct blocks and often exhibit various kinds of morphology resulting from the microphase separation of the polymer blocks. The AFM and SEM images of thin films of PLLA, PMMA and the block copolymers are shown in Fig. 10 and 
11, respectively. For the AFM results, the height images (left) and phase images (right) of the thin films are shown in Fig. 10. Worm-like (larger size) and spherical (smaller size) aggregates were uniformly distributed on the surface of the PLLA films (Fig. 10a and $\mathrm{a}^{\prime}$ ), and similar convex structures were also observed on the SEM images of the PLLA films (Fig. 11a). The aggregates appear to be isolated on the surface of the substrate in Fig. 11a and the height images of Fig. 10a, however, in the phase images (Fig. 10a'), these aggregates are bulged on the film. We suggested that the domains are formed by the crystallization of PLLA chains during the formation of PLLA thin films when the solvent evaporated. The larger aggregates
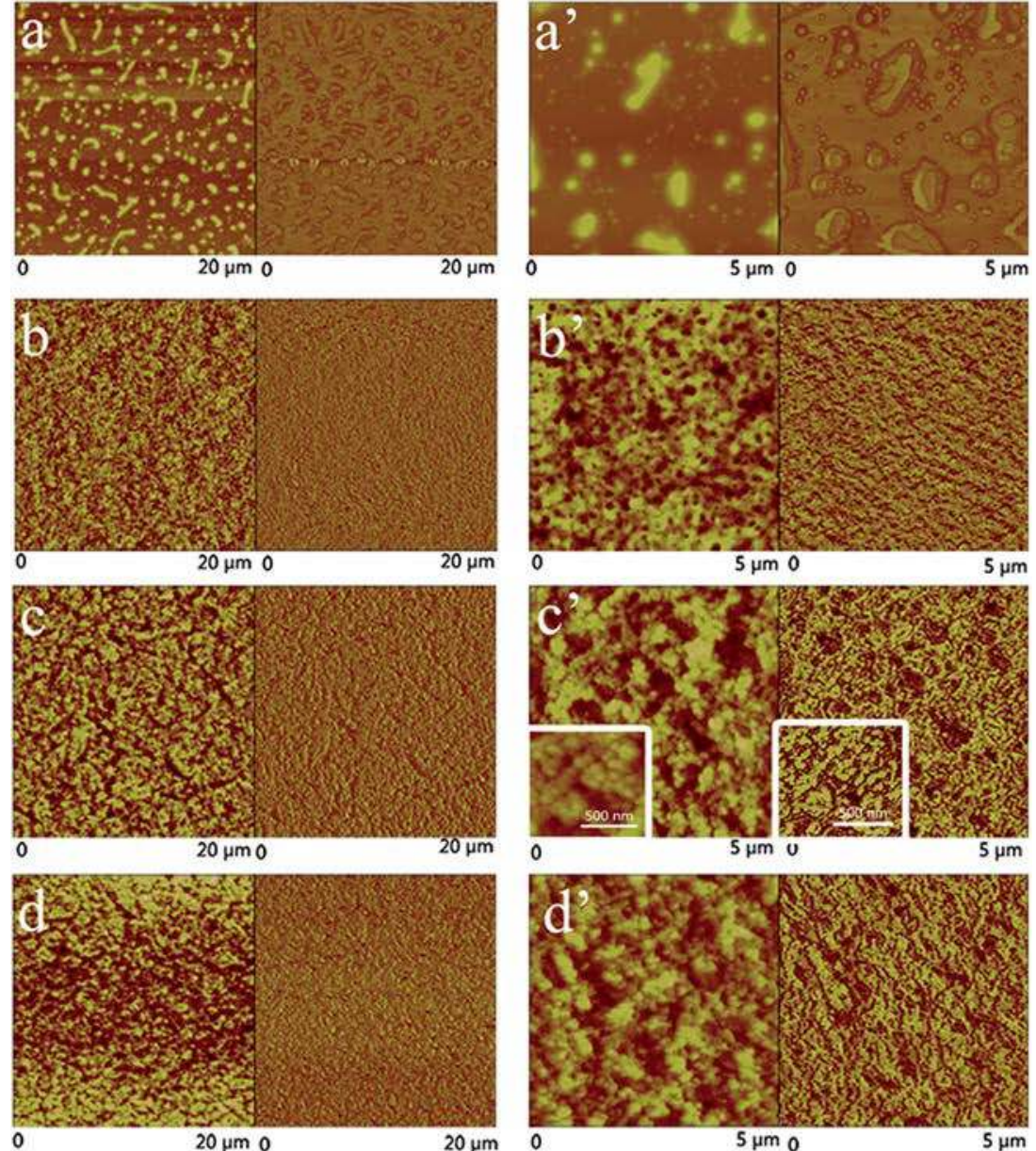

$20 \mu \mathrm{m} 0$
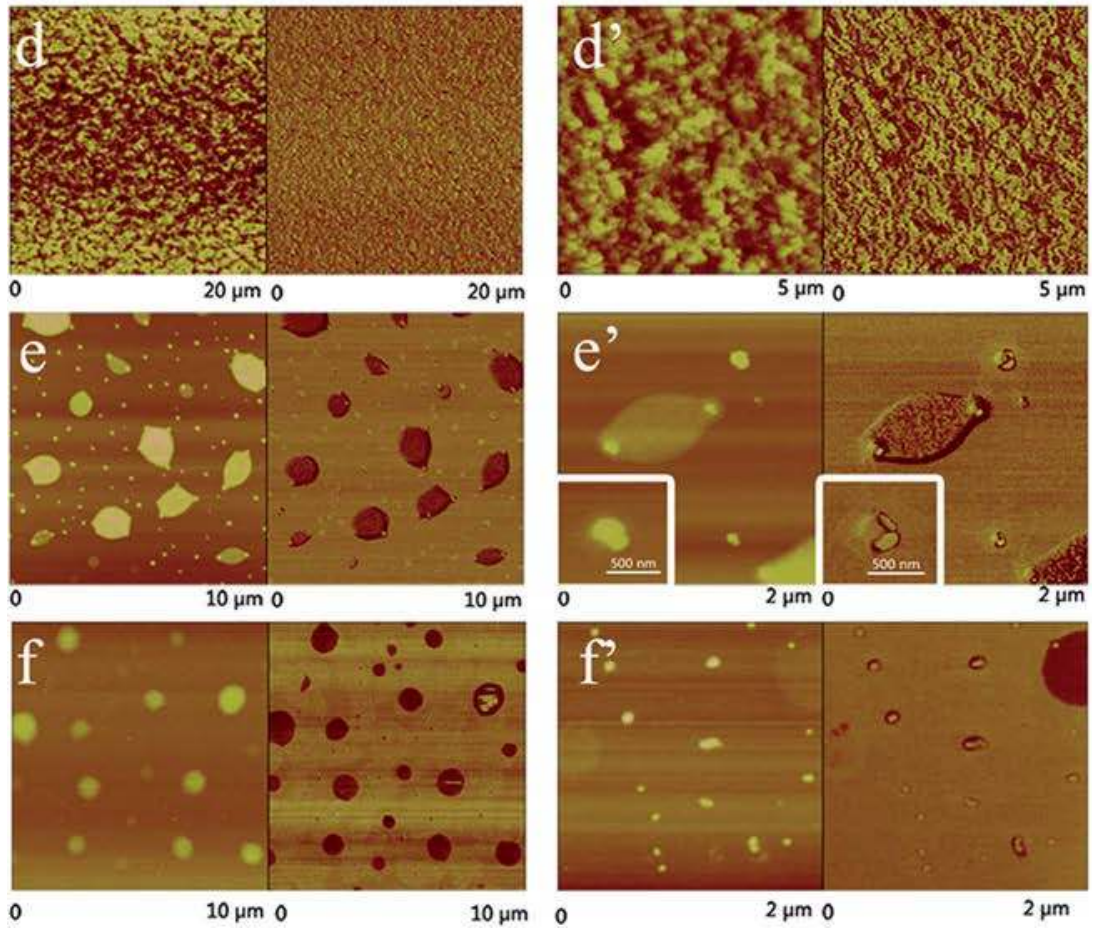

Fig. 10 AFM images (left: height, right: phase) of (a) and ( $\left.a^{\prime}\right)$ PLLA-Cl, MI-5, (b) and ( $\left.b^{\prime}\right)$ PMMA, (c) and (c') PLLA- $b-P M M A, B-7,(d)$ and (d') PLLA- $b-$ PMMA, B-8, (e) and (e') PLLA- $b-$ PtBA, B-9, (f) and ( $\left.f^{\prime}\right)$ PLLA- $b$-P2EHA, B-10. The insets in $\left(c^{\prime}\right)$ and $\left(d^{\prime}\right)$ are enlarged images of the copolymer film surface. 

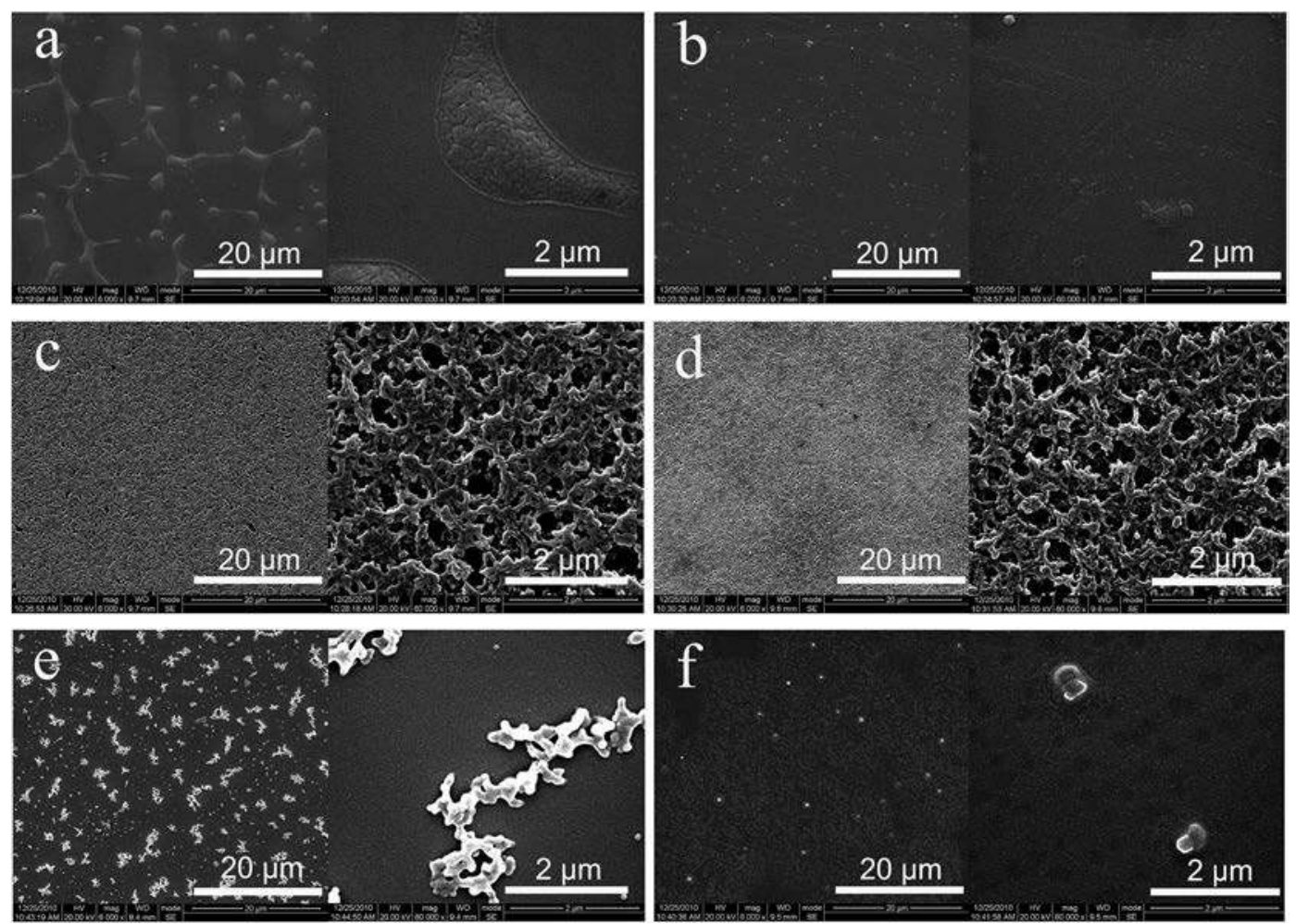

Fig. 11 SEM images of (a) PLLA-Cl, MI-5, (b) PMMA, (c) PLLA- $b-P M M A, B-7$, (d) PLLA- $b-P M M A, ~ B-8$, (e) PLLA- $b$-PtBA, B-9, (f) PLLA- $b$-P2EHA, B10 (scale bars for all images, left: $20 \mu \mathrm{m}$, right: $2 \mu \mathrm{m}$ ).

probably result from the combination of small spherical crystalline granules $(\sim 50 \mathrm{~nm})$ of PLLA (Fig. 11a, right). The surface of the PMMA thin films was very smooth as compared with that of PLLA (Fig. 10b and $\mathrm{b}^{\prime}$ and 11b) because PMMA is amorphous.

As shown in the low magnification AFM images (Fig. 10c and d), the surface morphology of the PLLA-b-PMMA (B7, B8) thin films was similar to that of pure PMMA. However, irregular holes and nodules were observed on the surface in the high magnification AFM images of these PLLA-b-PMMA (Fig. $10 \mathrm{c}^{\prime}$ and $\mathrm{d}^{\prime}$ ). The insets in Fig. 10c' show the sphere-shaped nodule structures in the PLLA-b-PMMA thin films. The sphere-shaped structures are probably formed by the microphase separation between the PLLA and PMMA blocks due to their immiscibility, ${ }^{39}$ the PLLA blocks could crystallize but the covalent bonds between these two blocks would force the PMMA blocks to surround the PLLA crystal "cores". As shown in Fig. 10d', the boundary between the sphere-shaped structures became blurred when the content of PLLA blocks in the copolymer decreased. From the SEM images of the PLLA-b-PMMA block copolymers (Fig. 11c and d), the copolymer thin films exhibited a relatively smooth surface at low magnification with micropores on the surface being observed at high magnification. These pores were well distributed when the content of PMMA blocks was dominant in the copolymer (B-8, Fig. 11d). As shown in the high magnification SEM images, the morphology of the micro-pores suggested an uneven structure, which might result from the micro-phase separation between amorphous PMMA and PLLA crystal domains, as noted above. The results revealed the possibility to fabricate porous membranes using the block copolymers, whose pores could be controlled by changing the ratio of blocks and the block lengths.

From the AFM and SEM images, the PLLA- $b$-PtBA and PLLAb-P2EHA exhibited different surface morphologies compared with that of PLLA-b-PMMA (Fig. 10e, $\mathrm{e}^{\prime}, \mathrm{f}$ and $\mathrm{f}^{\prime}$ and $11 \mathrm{e}$ and $\mathrm{f}$ ). It was observed that the domains of PLLA-b-PtBA and PLLA- $\boldsymbol{b}$ P2EHA copolymers are separate and distribute on the mica substrate. In the AFM phase images, the microphase separation can be observed for both the big domains $(0.5-1.3 \mu \mathrm{m})$ and the small ones (50-200 nm). The deep-gray area was assigned to the "soft" phase, which was formed by the PtBA and P2EHA blocks of the copolymers, while the light-gray area was assigned to the "hard" phase, which was formed by the PLLA blocks of the copolymers. PLLA crystallized and the PLLA domains are embedded in the PtBA or P2EHA domains. The content of PLLA blocks in PLLA-b-PtBA was higher than that in PLLA-b-P2EHA, and thus the size of the PLLA domains of PLLA- $b$-PtBA was larger than that of PLLA- $b$-P2EHA. Moreover, the PLLA- $b$-PtBA aggregates showed a clearer boundary and a bigger size than those of the PLLA- $\boldsymbol{b}$-P2EHA aggregates. This difference is due to the lower $T_{\mathrm{g}}$ of P2EHA. The samples were prepared from solution. The $T_{\mathrm{g}}$ of P2EHA is at about $-65^{\circ} \mathrm{C}$, so the P2EHA blocks are in "rubbery state" at room temperature. The AFM images of PLLA-b-P2EHA clearly showed that the P2EHA domains were distinct in the phase image but they almost disappeared in the height image, and this is also confirmed by the SEM results. In high magnification AFM images of the PLLA- $b$-PtBA and PLLA- 
b-P2EHA films (Fig. $10 \mathrm{e}^{\prime}$ and $\mathrm{f}^{\prime}$ ), it can be observed that PLLA crystals were embedded in either large-size or small-size copolymer aggregates, suggesting a microphase separation between the constituents. The copolymer aggregates of PLLA- $\boldsymbol{b}$ PtBA were observed to be discontinuous structures in the SEM images (Fig. 11e), but by AFM, the block copolymers were observed as domains (Fig. 10e and $\mathrm{e}^{\prime}$ ). A possible cause may be that the surface of the thin films were gold-coated before the SEM measurement. The difference between the SEM and AFM results of PLLA- $\boldsymbol{b}$-PtBA is more surprising when both AFM and SEM analyses have been performed on the same sample. For the SEM experiment, the sample has been metalized which may cause the aggregations of the domains because of the weak P $t \mathrm{BA}$ polymer bondings to the mica substrate. However, this was not observed for the PLLA-b-P2EHA (Fig. 11f) where no grain boundary of PLLA- $\boldsymbol{b}$-P2EHA aggregates was found on SEM images and the surface of the SEM images of copolymer PLLA- $\boldsymbol{b}$ P2EHA in Fig. 11f looks smooth.

\section{Conclusions}

We studied the block copolymers of lactide and 3 (meth)acrylates, using methyl methacrylate, tert-butyl acrylate and 2-ethylhexyl acrylate as monomers. The glass transition temperature $\left(T_{\mathrm{g}}\right)$ and the thermal stability of block copolymers could be tuned by changing the chain length of the blocks and the type of monomers. The copolymer PLLA- $\boldsymbol{b}$-PMMA was endowed with a higher heat distortion resistance by the introduction of PMMA blocks with a high $T_{\mathrm{g}}$, and the thermal stability of the copolymers could be improved and tuned by increasing the chain length of the PMMA blocks. The copolymer PLLA- $\boldsymbol{b}$-P2EHA showed a better thermal stability than that of PLLA- $\boldsymbol{b}$-PMMA and PLLA-b-PtBA. Moreover, the crystallization of the PLLA blocks was inhibited and we assume that the toughness of PLLA could be modified and tuned by poly(meth)acrylate blocks. The surface morphology of copolymer thin films made from different block copolymers differed greatly from each other. The surface of PLLA- $\boldsymbol{b}$-PMMA thin films showed a micropore structure, while copolymers PLLA- $\boldsymbol{b}$-PtBA and PLLA- $\boldsymbol{b}$-P2EHA had two different domains, indicating a microphase separation between the crystalline and amorphous polymers in the thin films.

\section{Acknowledgements}

The authors are grateful to the National Natural Science Foundation of China (No. 50873067), the Specialized Research Fund for the Doctoral Program of Higher Education of China (No. 20110181110032), the International Scientific and Technological Cooperation Projects of China (No. 2010DFA54460), the 2011 National Natural Science Foundation of China \& Centre National de la Recherche Scientifique (NSFC-CNRS) Joint Project (No. 51011130288) and the 2012 NSFC-CNRS Joint Project (No. 51211130101) for support of this research.

\section{References}

1 A. J. R. Lasprilla, G. A. R. Martinez, B. H. Lunelli, A. L. Jardini and R. M. Filho, Poly-lactic acid synthesis for application in biomedical devices - A review, Biotechnol. Adv., 2012, 30, 321-328.

2 M. Jamshidian, E. A. Tehrany, M. Imran, M. Jacquot and S. Desobry, Poly-lactic acid: production, applications, nanocomposites, and release studies, Compr. Rev. Food Sci. Food Saf., 2010, 9, 552-571.

3 K. M. Nampoothiri, N. R. Nair and R. P. John, An overview of the recent developments in polylactide (PLA) research, Bioresour. Technol., 2010, 101, 8493-8501.

4 X. Pang, X. L. Zhuang, Z. H. Tang and X. S. Chen, Polylactic acid (PLA): research, development and industrialization, Biotechnol. J., 2010, 5, 1125-1136.

5 A. Kumari, S. K. Yadav and S. C. Yadav, Biodegradable polymeric nanoparticles based drug delivery systems, Colloids Surf., B, 2010, 75, 1-18.

6 B. Bax and J. Müssig, Impact and tensile properties of PLA/ Cordenka and PLA/flax composites, Compos. Sci. Technol., 2008, 68, 1601-1607.

7 R. Auras, B. Harte and S. Selke, An overview of polylactides as packaging materials, Macromol. Biosci., 2004, 4, 835-864.

8 S. L. Yang, Z. H. Wu, W. Yang and M. B. Yang, Thermal and mechanical properties of chemical crosslinked polylactide (PLA), Polym. Test., 2008, 27, 957-963.

9 Y. Fan, H. Nishida, Y. Shirai and T. Endo, Thermal stability of poly(L-lactide): influence of end protection by acetyl group, Polym. Degrad. Stab., 2004, 84, 143-149.

10 C. F. Kuan, C. H. Chen, H. C. Kuan, K. C. Lin, C. L. Chiang and H. C. Peng, Multi-walled carbon nanotube reinforced poly(L-lactic acid) nanocomposites enhanced by watercrosslinking reaction, J. Phys. Chem. Solids, 2008, 69, 13991402.

11 M. Murariu, A. L. Dechief, L. Bonnaud, Y. Paint, A. Gallos, G. Fontaine, S. Bourbigot and P. Dubois, The production and properties of polylactide composites filled with expanded graphite, Polym. Degrad. Stab., 2010, 95, 889-900.

12 W. Zhang, Y. Zhang and Y. Chen, Modified brittle poly(lactic acid) by biodegradable hyperbranched poly(ester amide), Iran. Polym. J., 2008, 17, 891-898.

13 K. L. Pickering, M. A. Sawpan, J. Jayaraman and A. Fernyhough, Influence of loading rate, alkali fibre treatment and crystallinity on fracture toughness of random short hemp fibre reinforced polylactide biocomposites, Composites, Part A, 2011, 42, 1148-1156.

14 V. Vilay, M. Mariatti, Z. Ahmad, K. Pasomsouk and M. Todo, Improvement of microstructures and properties of biodegradable PLLA and PCL blends compatibilized with a triblock copolymer, Mater. Sci. Eng., A, 2010, 527, 69306937.

15 H. T. Liao and C. S. Wu, Preparation and characterization of ternary blends composed of polylactide, poly (E-caprolactone) and starch, Mater. Sci. Eng., A, 2009, 515, 207-214. 
16 B. Meng, J. Deng, Q. Liu, Z. Wu and W. Yang, Transparent and ductile poly(lactic acid)/poly(butyl acrylate) (PBA) blends: structure and properties, Eur. Polym. J., 2012, 48, 127-135.

17 Y. Lemmouchi, M. Murariu, A. M. D. Santos, A. J. Amass, E. Schacht and P. Dubois, Plasticization of poly(lactide) with blends of tributyl citrate and low molecular weight poly(D,L-lactide)- $b$-poly(ethylene glycol) copolymers, Eur. Polym. J., 2009, 45, 2839-2848.

18 T. P. Lodge, Block copolymers: past successes and future challenges, Macromol. Chem. Phys., 2003, 204, 265-273.

19 N. Hadjichristidis, M. Pitsikalis and H. Iatrou, Synthesis of block copolymers, Adv. Polym. Sci., 2005, 189, 1-124.

$20 \mathrm{~W}$. Jakubowski and K. Matyjaszewski, New segmented copolymers by combination of atom transfer radical polymerization and ring opening polymerization, Macromol. Symp., 2006, 240, 213-223.

21 L. Tao, B. Luan and C. Y. Pan, Block and star block copolymers by mechanism transformation. VIII Synthesis and characterization of triblock poly(LLA- $b$-St- $b$-MMA) by combination of ATRP and ROP, Polymer, 2003, 44, 10131020.

22 J. M. Messman, A. D. Scheuer and R. F. Storey, Synthesis and characterization of A-B-A triblock copolymers derived from chloro-telechelic poly(L-lactide): combining ring-opening polymerization (ROP) and atom transfer radical polymerization (ATRP), Polymer, 2005, 46, 3628-3638.

23 D. J. Liaw, C. C. Huang and J. Y. Ju, Novel multifunctional polymeric materials with predominant cis microstructures derived from a-norbornenyl macromonomer and stable macroinitiator via ring-opening metathesis polymerization and atom transfer radical polymerization, J. Polym. Sci., Part A: Polym. Chem., 2006, 44, 3382-3392.

24 F. F. Wolf, N. Friedemann and H. Frey, Poly(lactide)-blockpoly(HEMA) block copolymers: an orthogonal one-pot combination of ROP and ATRP, using a bifunctional initiator, Macromolecules, 2009, 42, 5622-5628.

25 K. Sha, D. S. Li, Y. P. Li, X. T. Liu, S. W. Wang, J. Q. Guan and J. Y. Wang, Synthesis, characterization, and micellization of an epoxy-based amphiphilic diblock copolymer of $\varepsilon^{-}$ caprolactone and glycidyl methacrylate by enzymatic ringopening polymerization and atom transfer radical polymerization, J. Polym. Sci., Part A: Polym. Chem., 2007, 45, 5037-5049.

26 C. J. Hawker, J. L. Hedrick, E. E. Malmström, M. Trollsås, D. Mecerreyes, G. Moineau, Ph. Dubois and R. Jérôme, Dual living free radical and ring opening polymerizations from a double-headed initiator, Macromolecules, 1998, 31, 213-219.

27 M. Dirany, P. Lacroix-Desmazes, M. Vayer, R. Erre, B. Boutevin and C. Sinturel, Polystyrene-block-polylactide obtained by the combination of atom transfer radical polymerization and ring-opening polymerization with a commercial dual initiator, J. Appl. Polym. Sci., 2011, 122, 2944-2951.
28 K. Sha, D. S. Li, S. W. Wang, L. Qin and J. Y. Wang, Synthesis and characterization of diblock copolymer by enzymatic ring-opening polymerization and ATRP from a novel bifunctional initiator, Polym. Bull., 2005, 55, 349-355.

29 K. Sha, D. S. Li, Y. P. Li, P. Ai, W. Wang, Y. X. Xu, X. T. Liu, M. Z. Wu, S. W. Wang, B. Zhang and J. Y. Wang, The chemoenzymatic synthesis of AB-type diblock copolymers from a novel bifunctional initiator, Polymer, 2006, 47, 4292-4299.

30 W. W. Wang, W. Y. Ren, L. Jiang and Y. Dan, Synthesis and characterization of AB-type copolymers poly(L-lactide)-blockpoly(methyl methacrylate) via a convenient route combining ROP and ATRP from a dual initiator, J. Appl. Polym. Sci., 2010, 118, 2379-2388.

31 C. C. Cypcar, P. Camelio, V. Lazzeri, L. J. Mathias and B. Waegell, Prediction of the glass transition temperature of multicyclic and bulky substituted acrylate and methacrylate polymers using the energy, volume, mass (EVM) QSPR model, Macromolecules, 1996, 29, 8954-8959.

32 K. Arabeche, L. Delbreilh, R. Adhikari, G. H. Michler, A. Hiltner, E. Baer and J.-M. Saiter, Study of the cooperativity at the glass transition temperature in $\mathrm{PC} /$ PMMA multilayered films: influence of thickness reduction from macro- to nanoscale, Polymer, 2012, 53, 1355-1361.

33 B. A. Bhanvase, D. V. Pinjari, S. H. Sonawane, P. R. Gogate and A. B. Pandit, Analysis of semibatch emulsion polymerization: role of ultrasound and initiator, Ultrason. Sonochem., 2012, 19, 97-103.

34 A. Vora, M. J. Nasrullah and D. C. Webster, Novel tailor-made diols for polyurethane coatings using a combination of controlled radical polymerization, ring opening polymerization, and click chemistry, J. Coat. Technol. Res., 2010, 7, 409-417.

35 Y. Murai, S. Asaoka and M. Yoshikawa, Polymeric pseudoliquid membrane as a stable liquid membrane-evidence for carrier-diffusion mechanism, J. Membr. Sci., 2011, 380, 216-222.

36 S. Monge, V. Darcos and D. M. Haddleton, Effect of DMSO used as solvent in copper mediated living radical polymerization, J. Polym. Sci., Part A: Polym. Chem., 2004, 42, 6299-6308.

37 M. Yasuniwa, S. Tsubakihara, Y. Sugimoto and C. Nakafuku, Thermal analysis of the double-melting behavior of poly(Llactic acid), J. Polym. Sci., Part B: Polym. Phys., 2004, 42, 2532.

38 R. M. Johnson and C. L. Fraser, Iron tris(bipyridine)centered star block copolymers: chelation of triblock macroligands generated by ROP and ATRP, Macromolecules, 2004, 37, 2718-2727.

39 J. Eckelt, S. Enders, M. D. C. Gonçalves, D. P. Queiroz and B. A. Wolf, Polydispersity effects on the phase diagram of the system chloroform/poly-L-(lactic acid)/poly(methyl methacrylate) and morphology of PLA/PMMA films, Fluid Phase Equilib., 2000, 171, 219-232. 